\title{
Building bridges between global information systems on marine organisms and ecosystem models
}

\author{
Grüss Arnaud 1, 2, * , Palomares Maria L. D. ${ }^{3,{ }^{*}}$, Poelen Jorrit H. ${ }^{4,}{ }^{\star}$, Barile Josephine R. ${ }^{5,}$,

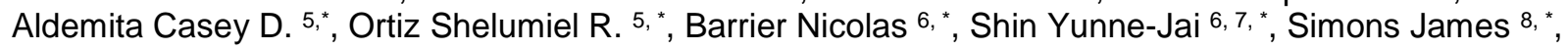 \\ Pauly Daniel ${ }^{3, *}$
}

1 Univ Miami, Rosenstiel Sch Marine \& Atmospher Sci, Dept Marine Biol \& Ecol, 4600 Rickenbacker Causeway, Miami, FL 33149 USA.

2 Univ Washington, Sch Aquat \& Fishery Sci, Box 355020, Seattle, WA 98105 USA.

3 Univ British Columbia, Inst Oceans \& Fisheries, Sea Around Us, Vancouver, BC V6T 1Z4, Canada.

4400 Perkins St,Apt 104, Oakland, CA 94610 USA.

${ }^{5}$ Quantitat Aquat, IRRI Khush Hall, Laguna 4031, Philippines.

6 Univ Montpellier, IFREMER, CNRS, MARBEC,IRD, PI Eugene Bataillon,CC093, F-34095 Montpellier 5, France.

7 Univ Cape Town, Marine Res Inst, Dept Biol Sci, Private Bag X3, ZA-7701 Cape Town, South Africa. 8 Texas A\&M Univ, Ctr Coastal Studies, Nat Resources Ctr, 6300 Ocean Dr, Corpus Christi, TX 78412 USA.

Corresponding authors : email addresses : gruss.arnaud@gmail.com ; m.palomares@oceans.ubc.ca ; ihpoelen@xs4all.nl ; j.barile@q-quatics.org ; cdesepeda@gmail.com ; s.ortiz@q-quatics.org ; nicolas.barrier@ird.fr ; yunne-jai.shin@ird.fr ; james.simons@tamucc.edu ; d.pauly@oceans.ubc.ca

\begin{abstract}
:
To facilitate the wider implementation of ecosystem modeling platforms and, thereby, to help advance ecosystem-based fisheries management (EBFM) worldwide, tools delivering a large quantity of inputs to ecosystem models are needed. We developed a web application providing OSMOSE ecosystem models with values for trophic, growth and reproduction parameters derived from data from two global information systems (FishBase and SeaLifeBase). Our web application guides the user through simple queries to extract information from FishBase and SeaLifeBase data archives, and it delivers all the configuration files necessary for running an OSMOSE model. Here, we present our web application and demonstrate it for the West Florida Shelf ecosystem. Our software architecture can serve as a basis for designing other advanced web applications using FishBase and SeaLifeBase data in support of EBFM.
\end{abstract}




\section{Highlights}

- We designed a web application providing parameter values to OSMOSE ecosystem models. These parameter values are derived from data from FishBase and SeaLifeBase. Our web application couples a user interface and an application programming interface. It delivers all the configuration files necessary for running an OSMOSE model. Other web applications supporting management can be designed with our framework.

Keywords : Web application, FishBase, SeaLifeBase, Ecosystem model, OSMOSE, Web application programming interface 


\section{Introduction}

Ecosystem-based fisheries management (EBFM), which recognizes the importance of non-target marine organisms, trophic dynamics, the abiotic environment and socio-economic factors in fisheries systems, has emerged as a key concept (Pikitch et al., 2004; Link, 2010; Harvey et al., 2016). Because they can simulate the effects of fishing, environmental stressors and management measures at multiple spatial and temporal scales, ecosystem models have become central tools for informing EBFM (Christensen and Walters, 2011; Collie et al., 2016; Grüss et al., 2017a). Major breakthroughs have been achieved in the field of ecosystem modeling over the past 25 years, resulting in the emergence of a diversity of modeling platforms, which allow tackling the numerous questions associated with EBFM (Plagányi, 2007; Fulton, 2010; Espinoza-Tenorio et al., 2012). O'Farrell et al. (2017) updated Plagányi (2007)'s seminal terminology and distinguished between six types of ecosystem models, based on their structure. These six types of ecosystem models are, in order of complexity: conceptual and qualitative models, extensions of single-species models, dynamic multispecies models, aggregated (or whole ecosystem) models, biogeochemical-based end-to-end models, and coupled and hybrid model platforms (O'Farrell et al., 2017).

Three of the most commonly used ecosystem modeling platforms belong to the most sophisticated types of ecosystem models: the aggregated (or whole ecosystem) modeling platform Ecopath with Ecosim (EwE) (Walters et al., 1997; Pauly et al., 2000; Christensen and Walters, 2004), the biogeochemical-based end-to-end modeling platform Atlantis (Fulton et al., 2004, 2007, 2011), and the individual-based, multispecies modeling platform OSMOSE, which belongs to the coupled and hybrid model platforms' type (Shin and Cury, 2001a, 2004; Grüss et al., 2016c). During the last decade, the trio EwE-Atlantis-OSMOSE has been increasingly employed to address EBFM questions such as the impacts of exploiting low trophic level species on marine ecosystems (Smith et al., 2011), the consequences of fishing scenarios on the structure of the Southern Benguela ecosystem (Smith et al., 2015), the performance of trophic level-based indicators for tracking fishing effects (Reed et al., 2017), the specificity of ecological indicators to fishing (Shin et al., 2018), and the synergistic impacts of fishing and environmental changes on marine ecosystems (Fu et al., 2018).

Despite the broad interest in EwE, Atlantis and OSMOSE for assisting EBFM, progress towards the wide use of these ecosystem modeling platforms (particularly Atlantis and OSMOSE) has been impeded by their large data requirements. Because they represent many of the components of marine ecosystems, from primary producers to large marine 
predators and humans, EwE, Atlantis and OSMOSE require an extremely large number of inputs (Fulton et al., 2007; Steele et al., 2013; Grüss et al., 2016a). As a result, the parameterization of EwE, Atlantis and OSMOSE models takes a relatively long time, while their calibration, which comes next before ecosystem models can be employed for simulations, is even more time-demanding (Oliveros Ramos, 2014; Ainsworth et al., 2015; Oliveros-Ramos et al., 2017). Therefore, to facilitate the wider implementation of sophisticated ecosystem modeling platforms such as EwE, Atlantis and OSMOSE and, thereby, to help advancing EBFM worldwide, there is a need for tools providing ecosystem models with a large quantity of inputs of reasonable quality (Grüss et al., 2016a; Coll and Steenbeek, 2017). Recent years have seen the creation of such tools. For example, probabilistic methods using maximum likelihood estimation have been developed for generating diet matrices for EwE and Atlantis models in a robust and relatively rapid manner (Ainsworth et al., 2010; Masi et al., 2014; Sagarese et al., 2016; Tarnecki et al., 2016; Morzaria-Luna et al., 2018). Another example are the statistical habitat methods that were designed for producing annual and seasonal distribution maps in bulk for Atlantis and OSMOSE models (Grüss et al., 2017b, 2018a, 2018b, 2018c, 2019). However, none of these recently-created tools are user-friendly, and they do not cover many of the important trophic (e.g., Ecopath's consumption rates, OSMOSE's predator/prey size ratios), growth and reproduction parameters required by EwE, Atlantis and OSMOSE.

The most efficient way to provide the largest possible number of inputs of reasonable quality to EwE, Atlantis and OSMOSE models would be to create a tool for querying large global information systems on marine organisms, namely FishBase (http://www.fishbase.org; Froese and Pauly, 2018) and SeaLifeBase (http://www.sealifebase.org/; Palomares and Pauly, 2018). FishBase is the world's largest database on fish on the web; it supplies taxonomic, ecological, morphological and metabolic information on 34,000 species and subspecies as of June 2018 (Froese and Pauly, 2018). SeaLifeBase is a large global information system similar to FishBase, which covers all types of marine organisms apart from fish; as of June 2018, it includes information for 75,100 non-fish species (Palomares and Pauly, 2018). In the "Tools" section of FishBase, a routine provides some EwE parameters for aquatic ecosystems and national waters within Food and Agriculture Organization (FAO) areas. However, this routine is basic and supplies only a couple of inputs for the Ecopath component of EwE (e.g., trophic levels (TLs), consumption rates) on a webpage. Also, this routine assigns species to functional groups (i.e., groups of species sharing similar life history traits and ecological niches), based 
on their maximum body length, habitat and depth range, but also based on their family, which results in the definition of many more functional groups than usually defined in EwE models. Lastly, this routine focuses on fish, while many other types of marine organisms, including invertebrates, marine mammals, sea turtles and seabirds, are usually represented in EwE models. Therefore, it would be advantageous to develop more sophisticated tools establishing bridges between both FishBase and SeaLifeBase and ecosystem modeling platforms like EwE, Atlantis and OSMOSE, so as to provide the largest possible number of trophic, growth and reproduction parameters of reasonable quality to these ecosystem modeling platforms.

In this study, we present the web application we developed for providing OSMOSE models with values for trophic, growth and reproduction parameters derived from FishBase and SeaLifeBase data. Our web application combines a web user interface (web UI) ${ }^{1}$ guiding the user through simple queries with a web application programming interface (web API) ${ }^{2}$ and data archives for retrieving and managing FishBase and SeaLifeBase data, and it ultimately delivers a zip file containing all the information necessary for running an OSMOSE model. Although our initial intent was to create a web application for helping the parameterization of OSMOSE models, we developed a framework that is as generic as possible, so as to enable its future use for designing web applications capable of processing FishBase/SeaLifeBase data to produce parameter values for other sophisticated ecosystem models (e.g., Atlantis applications). In the following, we first describe the OSMOSE modeling platform, its inputs, and its requirements. Then, we provide an overview of our web application, before presenting the different steps that are followed to ultimately deliver OSMOSE inputs to the user. Next, we demonstrate our web application for the West Florida Shelf, an ecosystem located within the Gulf of Mexico. Finally, we discuss the strengths and limitations of our web application in its current form and provide avenues for future research.

\section{Material and methods}

\subsection{The OSMOSE modeling platform}

\footnotetext{
${ }^{1}$ A web user interface (web UI) is a shared boundary between a web application and humans, designed to facilitate the exchange of information between the two entities.

${ }^{2}$ A web application programming interface (web API) is an ensemble of routine definitions, protocols and tools for implementing a web application.
} 
OSMOSE (Object-oriented Simulator of Marine ecOSystEms) is a two-dimensional, individual-based, multi-species modeling platform created around 20 years ago (Shin, 2000; Shin and Cury, 2001a, 2004; http://www.osmose-model.org). OSMOSE models simulate the entire life cycle of (typically 10 to 15) "focal functional groups" and their trophic interactions. In addition, OSMOSE models are forced by the biomass of a second type of functional groups called "biotic resources" (usually plankton and benthos groups), which only serve to provide extra food to the modeled system (Grüss et al., 2016b, 2016c). OSMOSE was initially developed for simulating the life cycle of individual focal species rather than that of focal functional groups (Shin, 2000; Shin and Cury, 2001a, 2004). Existing OSMOSE applications represent focal species (e.g., Marzloff et al., 2009; Halouani et al., 2016), focal functional groups (e.g., Brochier et al., 2013; Grüss et al., 2015), or a mix of the two (e.g., OliverosRamos et al., 2017; Xing et al., 2017). Our web application initially defines focal functional groups for the user, but let the user the possibility to define only focal species for their OSMOSE model if they wish (see Subsection 2.3.2).

The focal functional groups and biotic resources considered in OSMOSE models are usually only fish and invertebrate groups. An exception to this usual pattern is the focal marine mammal group (harbor seal, Phoca vitulina) represented in the OSMOSE model of the Strait of Georgia in British Columbia, Canada (Fu et al., 2012, 2013). However, the processes currently represented in OSMOSE are not well suited for simulating the biology and ecology of marine mammals and other organisms such as sea turtles and seabirds, which are, in many aspects, different from the biology and ecology of fish and invertebrates. Therefore, it is recommended to focus on fish and invertebrates in OSMOSE applications, and those are the two types of marine organisms for which our web application currently provides input parameters.

The key difference between OSMOSE and EwE and Atlantis is that OSMOSE does not use a diet matrix as input, but rather relies on the tenet that predation is an opportunistic and size-based process. Thus, OSMOSE lets diet compositions emerge from simulated trophic interactions (Shin and Cury, 2001a, 2004; Grüss et al., 2016c). In OSMOSE, the predation process is conditioned by three types of input: (1) spatial distribution maps, which, along with the random walk movements simulated for focal functional groups, define the annual or seasonal spatial distributions of marine organisms and, consequently, patterns of spatial overlap between predators and their potential prey; (2) minimum and maximum predator prey size ratios, which govern size adequacy between predators and their potential prey; and (3) 
accessibility coefficients, which determine if potential prey items are accessible to the predators, because of implicit, underlying factors such as distribution in the water column and animal morphology (e.g., presence of spikes) (Grüss et al., 2016c).

The basic units of OSMOSE models are "schools", namely individuals of a given focal functional group, which have the same age, body size, body weight, and, at a given time step, the same geographical location (Shin and Cury, 2001a, 2004). At each time step, schools undergo a series of processes: spatial distribution and random walk movement, then mortality processes (predation, starvation and fishing mortalities, and other mortality due to causes not explicitly modeled in OSMOSE), then growth in size and weight, and, finally, reproduction, which results in the production of age-0 schools for the next time step (Appendix A; Grüss et al., 2016c). The individual-based structure of OSMOSE allows one to track ecological information at different hierarchical levels: school, cohort (age class), focal functional group, and ecological community (Shin et al., 2004; Grüss et al., 2015; Travers-Trolet et al., 2014a).

OSMOSE has gone through three versions, and the last version itself has gone through two updates ("OSMOSE v3u1" and (“OSMOSE v3u2”) (Table 1). OSMOSE has served to address various EBFM questions, including the consequences of fishing scenarios on the structure and functioning of marine ecosystems (Shin et al., 2004; Marzloff et al., 2009; Travers et al., 2010; Smith et al., 2011, 2015), the effects of marine protected areas (MPAs) (Shin and Cury, 2001b; Yemane et al., 2009; Brochier et al., 2013), the impacts of environmental changes in fisheries systems (Fu et al., 2012, 2013; Travers-Trolet et al., 2014b), the sensitivity of ecological indicators and their specificity to fishing (Reed et al., 2017; Fu et al., 2018; Shin et al., 2018; Halouani et al., 2019), the estimation of predation mortality rates (Travers and Shin, 2010; Travers et al., 2009; Grüss et al., 2015, 2016c; Fu et al., 2017; Xing et al., 2017), and management strategy evaluation (MSE) in an ecosystem context (Grüss et al., 2016b). 
Table 1

Versions of the OSMOSE modeling platform and their applications.

\begin{tabular}{|c|c|}
\hline OSMOSE version & Applications \\
\hline OSMOSE v1 & $\begin{array}{l}\text { Theoretical ecosystems (Shin and Cury, 2001a, 2001b; Vergnon et al., 2008), Southern } \\
\text { Benguela ecosystem for the 1980s period (Shin et al., 2004; Travers et al., 2006; } \\
\text { Yemane et al., 2009) }\end{array}$ \\
\hline OSMOSE v2 & $\begin{array}{l}\text { Southern Benguela ecosystem for the 1990s period (Travers and Shin, 2010; Travers et } \\
\text { al., 2009, 2010; Travers-Trolet et al., 2014a, 2014b), Humboldt for the period 2000- } \\
2006 \text { (Marzloff et al., 2009), Bamboung Bolong in Senegal for the 2000s period } \\
\text { (Brochier et al., 2013), Strait of Georgia in Canada for the 2000s period (Fu et al., 2012, } \\
\text { 2013) }\end{array}$ \\
\hline OSMOSE v3 & West Florida Shelf ecosystem for the 2000s period (Grüss et al., 2015) \\
\hline OSMOSE v3u1 & West Florida Shelf ecosystem for the 2000s period (Grüss et al., 2016c) \\
\hline OSMOSE v3u2 & $\begin{array}{l}\text { West Florida Shelf ecosystem for the 2000s period (Grüss et al., 2016b), Gulf of Gabes } \\
\text { in Tunisia for the 2000s period (Halouani et al., 2016, 2019), Humboldt for the period } \\
1992-2008 \text { (Oliveros-Ramos et al., 2017), west coast of Canada for the period 1950- } \\
2014 \text { (Fu et al., 2017), Jiaozhou Bay in China for the 2000s period (Xing et al., 2017) }\end{array}$ \\
\hline
\end{tabular}

The version of OSMOSE considered in the present study is the latest one, i.e.

OSMOSE v3u2, which is available for download from http://www.osmose-

model.org/downloads. The two main characteristics of OSMOSE v3u2 are that: (1) it employs a "stochastic mortality algorithm" to compute mortality rates, which assumes that all types of mortalities are simultaneous processes and that there is competition and stochasticity in the predation process; and (2) it implements a "seeding process", which helps guarantee population persistence at the initialization of the modeled system (Appendix A; Grüss et al., 2016b). A user guide (https://documentation.osmose-model.org/) and GitHub repositories (https://github.com/osmose-model) are currently being developed for OSMOSE. The programming language used for implementing OSMOSE is Java (Gosling, 2000). An Integrated Development Environment (IDE) such as the free, open-source IDE NetBeans (https://netbeans.org/) can be utilized to compile OSMOSE models. OSMOSE models can also be run within the R environment with R package "osmose", which is now available on CRAN.

Two types of input files (“configuration files”) are fed into OSMOSE: CSV (commaseparated value) and netCDF files (http://www.osmose-model.org). The CSV and netCDF files provided to the template version of OSMOSE v3u2 (i.e., the version that can be downloaded from http://www.osmose-model.org/downloads) are detailed in Table 2 and Appendix B. The template version of OSMOSE v3u2 is based on the OSMOSE model for the Southern Benguela ecosystem for the 1990s period (Travers and Shin, 2010; Travers et al., 2009, 2010; Travers-Trolet et al., 2014a, 2014b). The great majority of OSMOSE 
configuration files use the key-value system to inform OSMOSE parameterization (e.g., "simulation.nspecies" is the key for the number of focal functional groups represented, and " 15 " is a potential value for this parameter; Appendix B). Numerous inputs are needed for focal functional groups, because their entire life cycle is modeled explicitly. In contrast, since biotic resources only serve to provide additional food to the modeled system, only a limited number of inputs are required for them, viz: biomass fields for the different time steps within a year considered in the OSMOSE model, minimum and maximum body sizes, TL, and availability and theoretical accessibility coefficients (Table 2 and Appendix B). Usually, two types of OSMOSE inputs are estimated during the calibration process of OSMOSE: the larval mortality rates of focal functional groups, and the availability coefficients of biotic resources (Travers-Trolet et al., 2014a; Grüss et al., 2015).

\section{Table 2}

Details about the CSV (.csv) and netCDF (.nc) configuration files supplied to the template version of OSMOSE v3u2. Details about the parameters provided by these CSV and netCDF files are given in Appendix B. $n=$ number of focal functional groups represented in the OSMOSE model.

\begin{tabular}{|c|c|}
\hline Configuration file name & Description \\
\hline osm_all-parameters.csv & $\begin{array}{l}\text { Main OSMOSE configuration file, where general OSMOSE } \\
\text { parameters, such as the number of time steps per year and the } \\
\text { number of focal functional groups and biotic resources considered, } \\
\text { are provided }\end{array}$ \\
\hline osm_param-species.csv & $\begin{array}{l}\text { File defining the basic parameters (e.g., growth parameters, } \\
\text { longevity) of focal functional groups }\end{array}$ \\
\hline osm_param-ltl.csv & $\begin{array}{l}\text { File defining the parameters of biotic resources (e.g. minimum and } \\
\text { maximum body sizes) }\end{array}$ \\
\hline osm_param-grid.csv & $\begin{array}{l}\text { File providing information about the spatial grid of the OSMOSE } \\
\text { model }\end{array}$ \\
\hline grid-mask.csv & Spatial grid of the OSMOSE model \\
\hline osm_ltlbiomass.nc & $\begin{array}{l}\text { File providing biomass fields for biotic resources for the different } \\
\text { annual time steps represented in the OSMOSE model }\end{array}$ \\
\hline osm_param-fishing.csv & File defining the exploitation patterns of focal functional groups \\
\hline osm_param-init-pop.csv & $\begin{array}{l}\text { File providing the initial biomasses (i.e., the biomasses at time step } \\
0 \text { ) of focal functional groups }\end{array}$ \\
\hline osm_param-movement.csv & $\begin{array}{l}\text { File defining the spatial distribution and movement patterns of focal } \\
\text { functional groups }\end{array}$ \\
\hline osm_param-natural-mortality.csv & $\begin{array}{l}\text { File defining the larval mortality rate of focal functional groups and } \\
\text { their non-larval mortality due to causes unrepresented in OSMOSE }\end{array}$ \\
\hline osm_param-predation.csv & $\begin{array}{l}\text { File defining the trophic parameters of focal functional groups (e.g., } \\
\text { their minimum and maximum predator/prey size ratios) }\end{array}$ \\
\hline osm_param-reproduction.csv & $\begin{array}{l}\text { File providing the names of the CSV files defining the seasonal } \\
\text { patterns of reproduction of focal functional groups }\end{array}$ \\
\hline osm_param-starvation.csv & $\begin{array}{l}\text { File defining the maximum annual starvation mortality rate of focal } \\
\text { functional groups }\end{array}$ \\
\hline predation-accessibility.csv & $\begin{array}{l}\text { File providing the accessibility coefficients of focal functional } \\
\text { groups and the theoretical accessibility of biotic resources; all these }\end{array}$ \\
\hline
\end{tabular}


coefficients define the accessibility of potential prey items to individual predators

reproductionseasonality- $\mathrm{sp}_{i} \cdot \mathrm{csv}$,

Files defining the seasonal patterns of reproduction of focal functional groups

with $i=0,1, \ldots, n-1$

fishing/fishing-seasonality-name ${ }_{i} . \mathrm{csv}$,

Files (located within a "fishing" folder) that define the seasonal patterns of exploitation of focal functional groups

Files (located within a "maps" folder) that define the spatial

maps/name ${ }_{i} j . \mathrm{csv}$,

distribution patterns of focal functional groups, possibly at different

seasons (if $j>1$ )

integer

File defining the specifics about OSMOSE outputs

Due to its ability to track ecological information at different hierarchical levels, OSMOSE can deliver a large number of outputs, at different levels of aggregation. Thus, for example, OSMOSE models can inform one about biomasses and body sizes at the cohort, focal functional group and ecological community levels (Shin et al., 2004; Marzloff et al., 2009; Grüss et al., 2015; Travers-Trolet et al., 2014a). The template version of OSMOSE $\mathrm{v} 3 \mathrm{u} 2$ can provide up to 31 different types of basic outputs, such as biomasses, mean body sizes in the catch or TLs (Appendix B). However, a diversity of more complex outputs (e.g., Shannon-Wiener index, Fishing-in-Balance index, net present value of discounted fisheries revenues) can be obtained from OSMOSE, either by modifying OSMOSE Java code or through a post-processing of OSMOSE basic outputs (e.g., Travers et al., 2006; Grüss et al., 2016b; Reed et al., 2017).

OSMOSE models are stochastic, because they: (1) distribute limited numbers of schools over space based on the distribution maps provided as input; (2) employ random walk movement to simulate the movements of schools within their distribution areas; and (3) use a "stochastic mortality algorithm" to compute mortality rates (Grüss et al., 2016b, 2016c). Consequently, OSMOSE outputs are analyzed on the basis of several OSMOSE replicates (generally 10 or 20; Marzloff et al., 2009; Travers et al., 2010; Grüss et al., 2015; Halouani et al., 2016).

\subsection{Overview of the web application}

Our web application relies on interactions between a web UI (https://doi.org/10.5281/zenodo.1418543) and a web API (https://doi.org/10.5281/zenodo.1411483) (Fig. 1). The user starts interacting with the web application by querying the web UI, which utilizes JavaScript and the JQuery library (Osmani, 2012). After the user has defined the study region, the web UI queries information 
stored in JavaScript Object Notation (JSON) data archives to define functional groups for the OSMOSE model. Then, the web UI offers the possibility to the user to redefine functional groups and the user is also requested to indicate the number of time steps per year of their OSMOSE model. Next, the information resulting from the interactions between the user and the web UI is passed to the web API. The web API queries the required FishBase and SeaLifeBase data (Table 3 and Appendix C) from TSV (tab-separated value) data archives and processes these data to generate OSMOSE input parameters, which are communicated to the web UI. The web API is coded in the Java programming language (Gosling, 2000) and is deployed on the Heroku platform (https://www.heroku.com/). Finally, the web UI delivers a zip file ("osmose_config.zip") to the user, which contains OSMOSE configuration files filled with information, as well as a "README" file and a CSV file listing the species making up the focal functional groups and biotic resources defined for the OSMOSE model. We employ GitHub to share, document and discuss our web application and the tools on which our web application relies (see https://github.com/osmose-model/osmose-model.github.io, https://github.com/osmose-model/osmose-web-api, and https://github.com/osmosemodel/osmose-web-api-js). The second of three aforementioned GitHub repositories archives all of the Java code of the web API, and it keeps track of the issues faced during the development and use of our web API, as well as reflections on future improvements or developments. The repository https://github.com/osmose-model/osmose-web-api-js provides the JavaScript library necessary for running our web API (https://doi.org/10.5281/zenodo.1411481). 


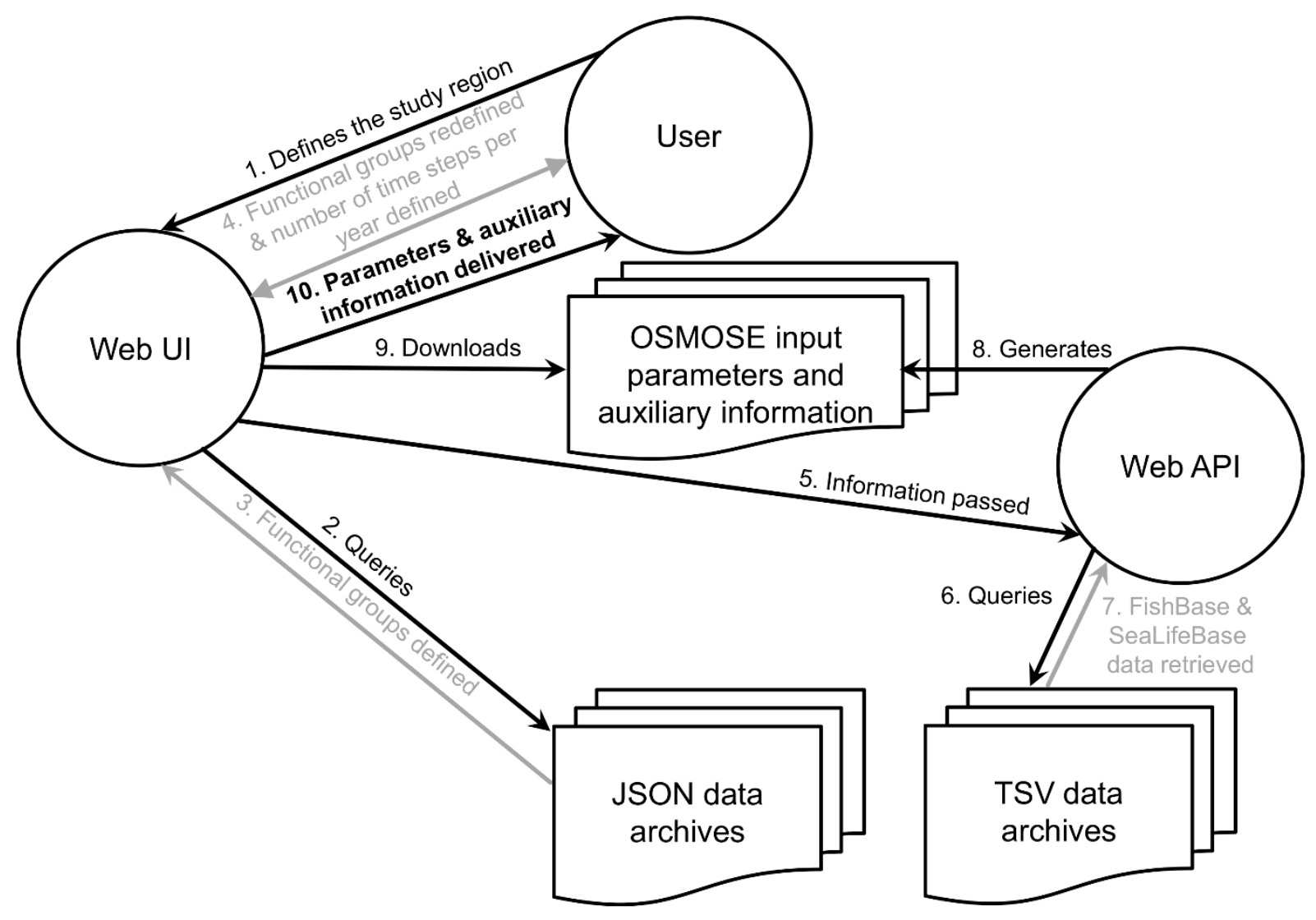

Fig. 1. Schematic of the different steps followed to obtain OSMOSE configuration files via the web application presented in this study. (1) The user starts interacting with the web user interface (web UI) and defines the study region. (2) The web UI queries data from JavaScript Object Notation (JSON) data archives to define functional groups and their species breakdown. (3) The defined functional groups are communicated to the web UI. (4) The user interacts with the web UI to redefine functional groups and to define the number of time steps per year in the OSMOSE model. (5) All the information resulting from the interactions between the user and the web UI is passed to the web application programming interface (web API). (6) The web API queries FishBase/SeaLifeBase data from TSV (tab-separated value) data archives. (7) The web API retrieves FishBase/SeaLifeBase data. (8) The web API processes the FishBase/SeaLifeBase data to generate OSMOSE input parameters. (9) The OSMOSE input parameters and auxiliary information are passed to the web UI. (10) The web UI communicates OSMOSE input parameters and auxiliary information to the user. 


\section{Table 3}

FishBase/SeaLifeBase's data used to derive OSMOSE parameters. Further details are provided in Appendix C. $X=0,1, \ldots, n_{X}-1$, where $n_{X}$ is the number of focal functional groups represented in the OSMOSE model. $\mathrm{Y}=0,1, \ldots, \mathrm{n}_{\mathrm{Y}}-1$, where $\mathrm{n}_{\mathrm{Y}}$ is the number of biotic resources represented in the OSMOSE model. * = FishBase/SeaLifeBase parameter used for calculating the "data richness" metric (see the main text for details on this metric).

\begin{tabular}{|c|c|c|c|}
\hline OSMOSE parameter & OSMOSE parameter key & $\begin{array}{l}\text { FishBase/ SeaLifeBase } \\
\text { table(s) to screen }\end{array}$ & $\begin{array}{l}\text { FishBase/ SeaLifeBase column(s) } \\
\text { to use }\end{array}$ \\
\hline Longevity (years) & species.lifespan.spX & species & LongevityWild* \\
\hline Instantaneous growth rate at small size $\left(\right.$ year $\left.^{-1}\right)$ & species.K.spX & popgrowth & $\mathrm{K}^{*}$ \\
\hline Maximum size $(\mathrm{cm})$ & species.IInf.spX & popgrowth & Loo* \\
\hline Theoretical age of zero length (years) & species.t0.spX & popgrowth & to* \\
\hline $\begin{array}{l}\text { Constant of proportionality of the allometric } \\
\text { length-weight relationship }\end{array}$ & species.length2weight.condition.factor.spX & poplw & $a^{*}$ \\
\hline $\begin{array}{l}\text { Exponent of the allometric length-weight } \\
\text { relationship }\end{array}$ & species.length2weight.allometric.power.spX & poplw & $b^{*}$ \\
\hline Body size at sexual maturity $(\mathrm{cm})$ & species.maturity.size.spX & maturity & $\mathrm{Lm}^{*}$ \\
\hline Age at sexual maturity (years) & species.maturity.age.spX & maturity & $\mathrm{tm}^{*}$ \\
\hline \multirow{4}{*}{$\begin{array}{l}\text { Threshold age below which a linear growth model } \\
\text { is used to calculate mean length increase (years) }\end{array}$} & \multirow[t]{4}{*}{ species.vonbertalanffy.threshold.age.spX } & poplw & LengthMin* \\
\hline & & popgrowth & to ${ }^{*}, \mathrm{Loo}^{*}, \mathrm{~K}^{*}$ \\
\hline & & estimate & AgeMin, AgeMax \\
\hline & & species & LongevityWild* \\
\hline \multirow[t]{2}{*}{ Annual number of eggs per $g$ of mature female } & \multirow[t]{2}{*}{ species.relativefecundity.spX } & \multirow[t]{2}{*}{ fecundity } & SpawningCycles*, \\
\hline & & & RelFecundityMean* \\
\hline $\begin{array}{l}\text { Sex ratio, defined as the proportion of females in } \\
\text { the population }\end{array}$ & species.sexratio.spX & spawning & SexRatiomid* \\
\hline Egg size $(\mathrm{cm})$ & species.egg.size.spX & eggs & Eggsdiammod* \\
\hline Egg weight (g) & species.egg.weight.spX & eggs & Eggsdiammod* \\
\hline Trophic level & plankton.TL.plkY & estimate & Troph* \\
\hline Minimum body size (cm) & plankton.size.min.plkY & popll & LengthMin* \\
\hline Maximum body size (cm) & plankton.size.max.plkY & popll & LengthMax* \\
\hline $\begin{array}{l}\text { Natural mortality rate due to causes unrepresented } \\
\text { in OSMOSE }\end{array}$ & mortality.natural.rate.spX & popqb & mortality* \\
\hline $\begin{array}{l}\text { Maximum annual ingestion rate ( } \mathrm{g} \text { of food per } \mathrm{g} \text { of } \\
\text { individual and per year) }\end{array}$ & predation.ingestion.rate.max.spX & popqb & PopQB* \\
\hline Critical predation efficiency & predation.efficiency.critical.spX & popqb & MaintQB*, PopQB* \\
\hline Minimum predator/prey size ratios & predation.predPrey.sizeRatio.max.spX & estimate & PredPreyRatioMin \\
\hline
\end{tabular}


Maximum predator/prey size ratios

Body size threshold that separates the predator/prey

size ratios for juvenile individuals from those for

adult individuals $(\mathrm{cm})$

Accessibility coefficients and theoretical

accessibility coefficients

Age threshold that separates the accessibility

coefficients of the juvenile and adult stages of foca

functional groups (years)

Reproduction seasonality
predation.predPrey.sizeRatio.min.spX

predation.predPrey.stage.threshold.spX

Content of the "predation-accessibility.csv"

file

predation.accessibility.stage.threshold.spX

Content of the "reproduction-seasonality-spX" spawning maturity

estimate

maturity
PredPreyRatioMax

Lm*

Benthic

$\operatorname{tm}^{*}$

Jan, Feb, Mar, Apr, May, Jun, Jul, Aug, Sep, Oct, Nov, Dec 


\subsection{Steps followed to provide OSMOSE inputs to the user}

\subsubsection{Definition of the study region}

To access the web UI, the user needs to go to the FishBase (http://www.fishbase.org) or SeaLifeBase website (http://www.sealifebase.org/), and to select the "OSMOSE parameters" radio button in the "Tools" section (Step 1 in Fig. 1). Then, the user reaches a first webpage, requesting them to select a marine ecosystem or a combination of a country and FAO area (Fig. 2). For some countries, it is also possible to select a given state (e.g., Louisiana in the U.S.) or province (e.g., Queensland in Australia). Once the study region has been defined, the user can press the "Proceed" button. Note that the web UI is also available at the following address: http://config.osmose-model.org.

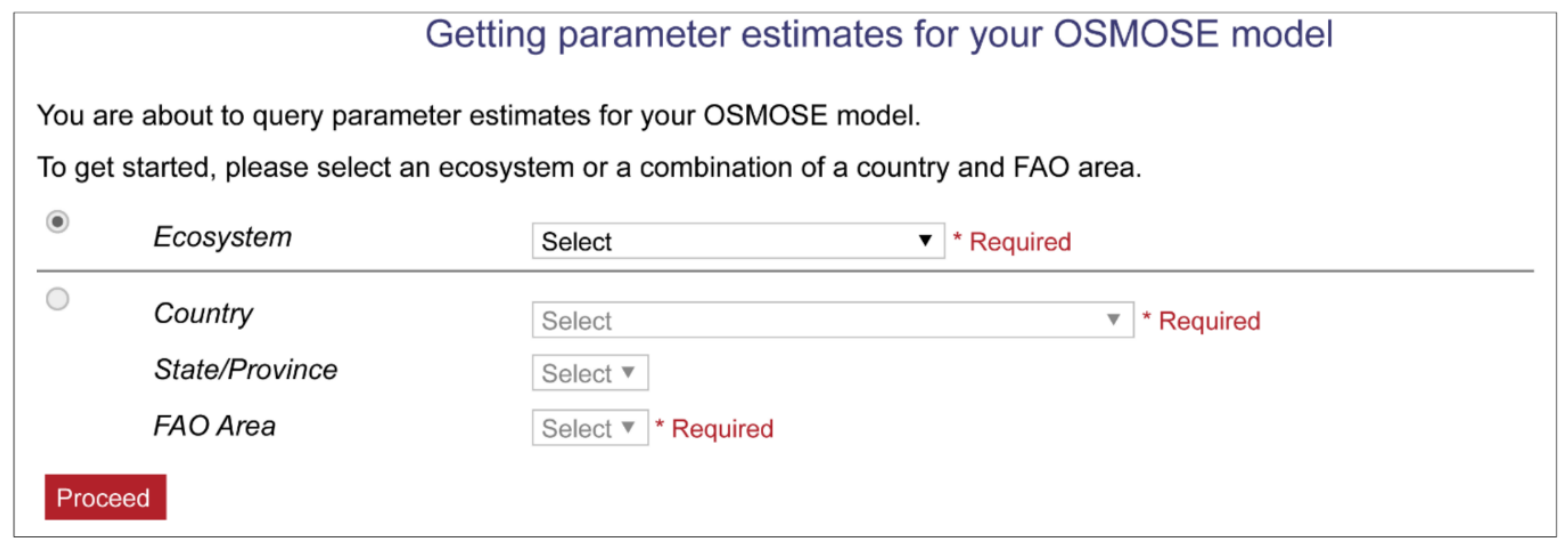

Fig. 2. Snapshot of the first page of the web user interface.

\subsubsection{Definition of functional groups and of the number of time steps per year}

To work on a first definition of functional groups and their species breakdown for the marine region defined by the user, the web UI queries information stored in JSON data archives we compiled (located in https://github.com/osmose-model/osmosemodel.github.io/tree/master/data) (Step 2 in Fig. 1). To populate the JSON data archives, we employed an existing routine ${ }^{3}$ to define functional groups for each of the marine regions (marine ecosystems and combinations of a country, FAO area and state/province) that can

\footnotetext{
${ }^{3}$ This (unpublished) routine is the routine used to provide some EwE parameters for aquatic ecosystems and national waters within FAO areas in the "Tools" section of FishBase (mentioned in the Introduction).
} 
potentially be selected by the user. This routine considers: (1) the species inhabiting the marine region of interest, according to FishBase and SeaLifeBase; and (2) the information stored in FishBase/SeaLifeBase's tables about the habitat (e.g., demersal, benthopelagic), depth range, body size and high order (e.g., sharks, rays) of these species. The JSON data archives also store the following information: (1) additional, related species (i.e., species that belong to a related genus or family) for each of the functional groups defined for each of the marine regions that can potentially be selected by the user (see Subsection 2.3.3); (2) the maximum body size, habitat and depth range of all the species included in the JSON data archives; and (3) "data richness" for all the species included in the JSON data archives (see below). The JSON data archives created for our web application are automatically updated every time changes are made in FishBase and SeaLifeBase (e.g., whenever mirror updates of FishBase and SeaLifeBase are performed).

After the web UI has queried information from the JSON data archives, the first definition of functional groups is displayed on a new webpage, along with two additional generic functional groups ("phytoplankton" and "zooplankton", which are both defined as biotic resources) and instructions for the user (Step 3 in Fig. 1 and Fig. 3). Functional groups are detailed in a table. A default name is assigned to them. Moreover, the class, Latin name, maximum body size, habitat and depth range of the species comprising the functional groups are provided. By default, all focal functional groups are defined as focal functional groups, except the generic phytoplankton and zooplankton groups, which can both only be defined as biotic resources. 


\section{Back Proceed}

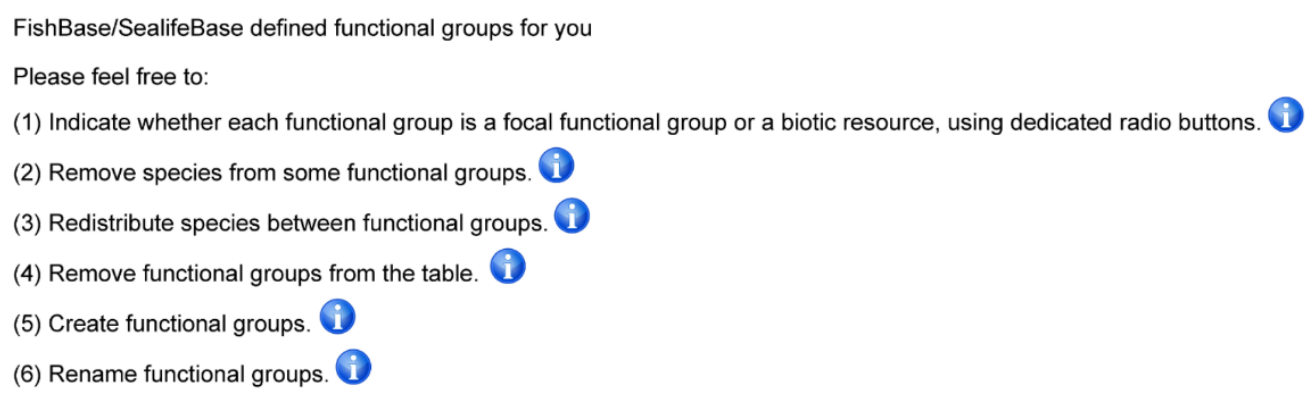

Caution: The name of the functional groups should not include spaces nor underscores. For example, "SmallPelagics" is a valid functional group name, but not "Small pelagics" nor "Small_pelagics".

When you are ready, press Proceed to go to the next step.

\begin{tabular}{|c|c|c|c|c|c|c|c|c|}
\hline $\begin{array}{l}\text { Select/ } \\
\text { deselect }\end{array}$ & Functional Group & \begin{tabular}{|c|} 
Focal \\
Functional \\
Group
\end{tabular} & $\begin{array}{c}\text { Biotic } \\
\text { Resource }\end{array}$ & Class & Species & $\begin{array}{c}\text { Maximum } \\
\text { length }(\mathrm{cm})\end{array}$ & Habitat & Depth \\
\hline$\checkmark$ & fishpelagicmd & - & 0 & $\nabla_{\text {Actinopterygii }}$ & $\checkmark$ Decapterus macarellus & 46 & pelagic-oceanic & 400 \\
\hline$\checkmark$ & fishdemeralsm & $\bullet$ & 0 & $\nabla_{\text {Actinopterygii }}$ & $\checkmark$ Hime japonica & 27.21 & demersal & $85-510$ \\
\hline$\checkmark$ & fishdemersalmd & - & 0 & $\checkmark$ Actinopterygii & $\checkmark$ Antigonia capros & 30.5 & demersal & $50-900$ \\
\hline$\checkmark$ & fishbathypelagicmd & $\bullet$ & 0 & $\checkmark$ Actinopterygii & $\checkmark$ Grammicolepis brachiusculus & 64 & bathypelagic & $300-1026$ \\
\hline$\checkmark$ & fishbenthopelagicmd & - & 0 & $\begin{array}{l}\checkmark \text { Actinopterygii } \\
\checkmark \text { Actinopterygii } \\
\checkmark \text { Actinopterygii }\end{array}$ & $\begin{array}{l}\checkmark \text { Beryx splendens } \\
\checkmark \text { Pentaceros wheeleri } \\
\checkmark \text { Zenopsis nebulosa }\end{array}$ & $\begin{array}{l}70 \\
44 \\
70\end{array}$ & $\begin{array}{l}\text { benthopelagic } \\
\text { benthopelagic } \\
\text { benthopelagic }\end{array}$ & $\begin{array}{l}25-1300 \\
146-800 \\
30-800\end{array}$ \\
\hline$\checkmark$ & fishbenthopelagiclg & - & 0 & $\begin{array}{l}\checkmark \text { Actinopterygii } \\
\checkmark \text { Actinopterygii } \\
\checkmark \text { Actinopterygii }\end{array}$ & $\begin{array}{l}\text { VEtelis carbunculus } \\
\checkmark \text { Promethichthys prometheus } \\
\checkmark \text { Ruvettus pretiosus }\end{array}$ & $\begin{array}{l}140.97 \\
122 \\
300\end{array}$ & $\begin{array}{l}\text { benthopelagic } \\
\text { benthopelagic } \\
\text { benthopelagic }\end{array}$ & $\begin{array}{l}90-400 \\
80-800 \\
100-800\end{array}$ \\
\hline$\checkmark$ & fishsharklg & - & 0 & $\checkmark$ Elasmobranchii & $\checkmark$ Squalus blainville & 100 & demersal & \\
\hline$\checkmark$ & zooplankton & $\bullet$ & 0 & & & & & \\
\hline$\checkmark$ & phytoplankton & - & 0 & & & & & \\
\hline \multicolumn{9}{|c|}{$\Theta$} \\
\hline Back & Proceed & & & & & & & \\
\hline
\end{tabular}

Fig. 3. Snapshot of the second page of the web user interface for the Academician Berg, a seamount ecosystem belonging to the Hawaiian-Emperor seamount chain, which is located in the North Pacific.

The species composition of the functional groups defined in the JSON data archives and displayed on the second page of the web UI was determined using a "data richness" metric. Data richness was calculated on the basis of 18 FishBase/SeaLifeBase parameters (Table 3). For each species that could potentially be included in a functional group, it was determined whether a value is available (1) or not (0) for each of the 18 FishBase/SeaLifeBase parameters to estimate data richness. For example, if, for a given species, 10 parameter values were available, the data richness of this species was equal to 10 . For each functional group, the species that could potentially be included were ranked based on their data richness and those whose data richness was smaller than 2 were dropped. Then, some other species with the lowest data richness values were eventually dropped so as to keep 
the number of species per functional group to a maximum of 30 , for the sake of computational efficiency.

In the case of the generic phytoplankton and zooplankton groups, species are not defined and, therefore, data richness is not calculated. Instead, pre-specified parameter values for phytoplankton and zooplankton (i.e., which are the same for all marine regions; Table 4) are provided in the OSMOSE configuration files. These parameter values are those that are usually defined in existing OSMOSE applications (e.g., Travers-Trolet et al., 2014a; Grüss et al., 2015; Halouani et al., 2016; Fu et al., 2017). The rationale behind the definition of generic phytoplankton and zooplankton groups is that preliminary results revealed that data richness is equal to 1 for the great majority of the zooplankton species included in SeaLifeBase and for all the phytoplankton species included in SeaLifeBase. However, for some marine regions, the web application may define specific zooplankton groups in addition to the generic zooplankton group. This possibility was allowed, because, in addition to representing zooplankton groups as biotic resources, some existing OSMOSE models (Travers-Trolet et al., 2014a; Fu et al., 2013, 2017) represented euphausiids (order Euphausiacea, class Malacostraca) as a focal functional group.

\section{Table 4}

Parameter values for the generic phytoplankton and zooplankton groups defined by the web application for any marine region. Both the generic phytoplankton and zooplankton groups are defined as "biotic resources" by the web application.

\begin{tabular}{llll}
\hline OSMOSE parameter & OSMOSE parameter key & $\begin{array}{l}\text { Value for } \\
\text { phytoplankton }\end{array}$ & Value for zooplankton \\
\hline Minimum body size $(\mathrm{cm})$ & plankton.size.min.plk & 0.0002 & 0.002 \\
Maximum body size $(\mathrm{cm})$ & $\begin{array}{l}\text { plankton.size.max.plk } \\
\text { Trophic level }\end{array}$ & 0.02 & 0.3 \\
$\begin{array}{l}\text { Theoretical accessibility } \\
\text { coefficients }\end{array}$ & $\begin{array}{l}\text { Content of the "plk } \\
\text { accessibility.csv" file }\end{array}$ & 1 & 2 \\
\hline
\end{tabular}

The user has the possibility to redefine functional groups (Step 4 in Fig. 1 and Fig. 3). First, a check box allows the user to select/deselect functional groups. Second, the user can modify the name of functional groups and redefine some focal functional groups as biotic resources. Third, check boxes are provided to the left of class names and Latin species names, which enable the user to deselect some classes or species if they wish. Fourth, "Edit" tools are 
provided to the right of class names and Latin species names, which allow the user to add classes or species to functional groups; suggestions are provided to the user as they start typing something. Lastly, a "Plus" button at the bottom of the table enables the user to add new functional groups to the table. A new functional group then needs to be defined either as a focal functional group, in which case the user needs to fill in the "Species" column, or as a biotic resource, in which case the user needs to fill in "Class" column; here, again, suggestions are provided to the user as they start typing something ${ }^{4}$. The check boxes, "Edit" tools and "Plus" button allow the user to define only focal species (i.e., focal functional groups all comprising one unique species) for their OSMOSE model if they wish. The redefined functional groups are for the local user only and are not saved in the JSON data archives.

Once the user is satisfied with the (re)definition of functional groups, they need to press "Proceed" to reach another webpage. This webpage offers the user the possibility to reorder focal functional groups. Then, the user needs to press "Proceed" to reach another, similar webpage, where they are invited to re-order biotic resources before proceeding to next webpage.

The next webpage requests the user to indicate the number of time steps per year of their future OSMOSE model (e.g., 12 if their future OSMOSE model has a monthly time step). Afterwards, the user needs to press "Proceed".

\subsubsection{Data query in TSV data archives}

In addition to the species comprising the defined functional groups that the user can see on the second page of the web UI, additional, related species (i.e., species that belong to a related genus or family) are included in each of the defined functional groups. We implemented this so as to maximize one's chances to obtain non-default values for the largest possible number of OSMOSE input parameters. For each functional group defined for each marine region that could be potentially selected by the user, potential additional species were added to the JSON data archives and ranked based on their data richness, similarly to what is

\footnotetext{
${ }^{4}$ A workaround to fill in the "Species" column for an additional biotic resource consists of: (1) temporarily defining the biotic resource as a "focal functional group"; (2) filling in the "Species" column"; and (3) redefining the functional group as a "biotic resource"; this workaround is mentioned by one of the "information buttons" of the web user interface.
} 
described in Subsection 2.3.2. Potential additional species whose data richness was smaller than 2 were dropped. Then, some other potential additional species were eventually dropped so as to keep the total (i.e., original plus additional) number of species per functional group to a maximum of 30 , for the sake of computational efficiency. In the final list of species making up a functional group in JSON data archives, the ranked list of original species precedes the ranked list of additional species.

The list of the species (i.e., original plus additional) comprising the functional groups and the number of time steps of the OSMOSE model are communicated to the web API via a JSON file (Step 5 in Fig. 1). The web API then queries FishBase and SeaLifeBase data from TSV data archives we compiled (compressed TSV files located in https://github.com/FiNFBSLB/fishbase-sealifebase-archive; https://doi.org/10.5281/zenodo.1418646) (Steps 6 and 7 in Fig. 1). The TSV data archives were created from the information stored in the JSON data archives, using the "rOpenSci FishBase API", which is the API to the backend Structured Query Language (SQL) database behind FishBase and SeaLifeBase (Boettiger et al., 2012). The TSV data archives are automatically updated every time changes are made in FishBase and SeaLifeBase (e.g., whenever mirror updates of FishBase and SeaLifeBase are performed).

\subsubsection{Generation of OSMOSE parameters}

The web API employs the data queried from the TSV data archives to derive values for OSMOSE parameters (Step 8 in Fig. 1). For each functional group, to generate a value for a given OSMOSE parameter, the web API deals with the species comprising the functional group in turn, based on their rank. The web API first considers the first-ranked species and, if FishBase/SeaLifeBase data are available for this species, then a value is calculated for the OSMOSE parameter. The web API then considers the second-ranked species and, if FishBase/SeaLifeBase data are available for this species, then a value is calculated for the OSMOSE parameter. This process continues until the web API reaches the last-ranked species of the functional group. If no FishBase/SeaLifeBase data are available for all of the species making up the functional group (i.e., original plus additional), then the OSMOSE parameter under consideration is set to its default value (Appendix C). NA (not available) is the default value of 11 of the OSMOSE parameters for which our web application provides estimates (Appendix C). 
The web API either determines the value of an OSMOSE parameter directly from a FishBase/SeaLifeBase parameter (e.g., longevity from the FishBase/SeaLifeBase parameter "LongevityWild"), or it generates an estimate for the OSMOSE parameter from calculations performed from several FishBase/SeaLifeBase parameters (e.g., critical predation efficiency is estimated from the FishBase/SeaLifeBase parameters "PopQB" and "MaintQB") (Table 3). It was necessary to add new columns to FishBase/SeaLifeBase tables to enable the estimation of some OSMOSE parameters. For example, we added the columns "PredPreyRatioMin" and "PredPreyRatioMax" to the FishBase/SeaLifeBase table "estimate" to enable the production of minimum and maximum predator/prey size ratio estimates for OSMOSE. When, for a given species, the web API encounters several values (usually originating from studies conducted in different regions) for a given FishBase/SeaLifeBase parameter in the TSV data archives, it generates a median estimate for that FishBase/SeaLifeBase parameter before doing any computations to derive an OSMOSE parameter estimate. Details about the generation of OSMOSE parameter values with the web API are given in Appendix C. All OSMOSE parameter values are entered by the web API into OSMOSE configuration files.

\subsubsection{Delivery of OSMOSE configuration files to the user}

Once the web API is done with the production of OSMOSE configuration files, an "osmose_config.zip" file is passed to the web UI, which contains the OSMOSE configuration files, as well as a CSV file listing the species making up the functional groups defined for the OSMOSE model ("functional_groups.csv") and a "README” file (Step 9 in Fig. 1). The README file is a spreadsheet, whose individual tabs describe the content of each OSMOSE configuration file. In each tab of the README file, information is provided about the individual OSMOSE parameters, their default value, whether and how they were estimated by the web application, and how they could be estimated if they are not covered by the web application (similarly to Appendix B).

At the time the web API delivers the "osmose_config.zip" file to the web UI, the user reaches a final webpage. This webpage informs the user that the configuration files for their OSMOSE model are ready, and it also provides information on where to download OSMOSE v3u2 and where to obtain technical assistance for OSMOSE. The user is instructed to press the "Submit" button to obtain the "osmose_config.zip" file (Step 10 in Fig. 1). 


\section{Results}

To demonstrate our web application, let us query OSMOSE configuration files for the West Florida Shelf region, which is located within the Gulf of Mexico Large Marine Ecosystem. The West Florida Shelf region is a marine ecosystem under strong and increasing anthropogenic and environmental pressures (Brand and Compton, 2007; Chagaris, 2013; Karnauskas et al., 2013, 2017). An OSMOSE model depicting the structure of the West Florida Shelf ecosystem in the 2000s, referred to as "OSMOSE-WFS", was developed in Grüss et al. (2015). The OSMOSE-WFS model was later updated in Grüss et al. (2016b, 2016c). OSMOSE-WFS has a monthly time step, explicitly considers 12 focal functional groups, and is forced by the biomass of seven biotic resources (Table 5). The two latest versions of the OSMOSE-WFS model (Grüss et al., 2016b, 2016c) used the parameter values defined in Grüss et al. (2015), except for the following parameters: (1) the minimum and maximum predator/prey size ratios of focal functional groups, which were redefined; and (2) the larval mortality rates of focal functional groups and the availability coefficients of biotic resources, which were re-estimated during the calibration process of OSMOSE. The parameter values employed in OSMOSE-WFS papers usually came from regional studies, or they were established based on experts' opinion (the accessibility coefficients of focal functional groups and the theoretical accessibility coefficients of biotic resources). Here, we compare the parameter values and functional relationships defined by our web application to the parameter values and functional relationships used in OSMOSE-WFS papers (Grüss et al., 2015, 2016b, 2016c). 


\section{Table 5}

Functional groups represented in the OSMOSE model of the West Florida Shelf ("OSMOSE-WFS"). These functional groups include focal functional groups, whose entire life cycle is simulated in the OSMOSE-WFS model, and biotic resources, whose biomass is used to force OSMOSE-WFS. Species of a given focal functional group exhibit similar life history characteristics, body size ranges, diets and exploitation patterns. Some individual species constitute their own focal functional group, as they are emblematic to the West Florida Shelf and of high economic importance. * = Classes for which there is currently no information available in SeaLifeBase.

\begin{tabular}{|c|c|c|}
\hline Functional group & $\begin{array}{l}\text { Focal functional group } \\
\text { or biotic resource? }\end{array}$ & Species making up the functional group \\
\hline King mackerel & Focal functional group & King mackerel (Scomberomorus cavalla) \\
\hline Amberjacks & Focal functional group & Greater amberjack (Seriola dumerili), lesser amberjack (Seriola fasciata), almaco jack (Seriola rivoliana) \\
\hline Red grouper & Focal functional group & Red grouper (Epinephelus morio) \\
\hline Gag & Focal functional group & Gag (Mycteroperca microlepis) \\
\hline Red snapper & Focal functional group & Red snapper (Lutjanus campechanus) \\
\hline $\begin{array}{l}\text { Sardine-herring-scad } \\
\text { complex }\end{array}$ & Focal functional group & $\begin{array}{l}\text { Scaled sardine (Harengula jaguana), Spanish sardine (Sardinella aurita), Atlantic thread herring (Opisthonema } \\
\text { oglinum), round scad (Decapterus punctatus), finescale menhaden (Brevoortia gunteri), Gulf menhaden } \\
\text { (Brevoortia patronus), Atlantic menhaden (Brevoortia tyrannus) }\end{array}$ \\
\hline Anchovies and silversides & Focal functional group & $\begin{array}{l}\text { Bay anchovy (Anchoa mitchilli), striped anchovy (Anchoa hepsetus), inland silverside (Menidia beryllina), } \\
\text { Alabama shad (Alosa alabamae) }\end{array}$ \\
\hline Coastal omnivores & Focal functional group & $\begin{array}{l}\text { Pinfish (Lagodon rhomboides), orange filefish (Aluterus schoepfii), fringed filefish (Monacanthus ciliatus), } \\
\text { orangespotted filefish (Cantherhines pullus), honeycomb filefish (Acanthostracion polygonius), Atlantic spadefish } \\
\text { (Chaetodipterus faber), scrawled cowfish (Acanthostracion quadricornis), bandtail puffer (Sphoeroides spengleri) }\end{array}$ \\
\hline Reef carnivores & Focal functional group & $\begin{array}{l}\text { White grunt (Haemulon plumierii), black sea bass (Centropristis striata), belted sandfish (Serranus subligarius), } \\
\text { butter hamlet (Hypoplectrus unicolor), creole fish (Paranthias furcifer), splippery dick (Halichoeres bivittatus), } \\
\text { yellowhead wrasse (Halichoeres garnoti), bluehead (Thalassoma bifasciatum), reef croaker (Odontoscion dentex), } \\
\text { jackknife-fish (Equetus lanceolatus), littlehead porgy (Calamus proridens), jolthead porgy (Calamus bajonado), } \\
\text { saucereye progy (Calamus calamus), whitebone progy (Calamus leucosteus), knobbed progy (Calamus nodosus), } \\
\text { French grunt (Haemulon flavolineatum), Spanish grunt (Haemulon macrostomum), margate (Haemulon album), } \\
\text { bluestriped grunt (Haemulon sciurus), striped grunt (Haemulon striatum), sailor's grunt (Haemulon parra), } \\
\text { porkfish (Anisotremus virginicus) }\end{array}$ \\
\hline Reef omnivores & Focal functional group & $\begin{array}{l}\text { Doctorfish (Acanthurus chirurgus), blue tang (Acanthurus coeruleus), blue angelfish (Holacanthus bermudensis), } \\
\text { gray angelfish (Pomacanthus arcuatus), rock beauty (Holacanthus tricolor), yellowtail damselfish } \\
\text { (Microspathodon chrysurus), bridled goby (Coryphopterus glaucofraenum), Bermuda chub (Kyphossus sectarix), } \\
\text { combtooth blenny (Chasmodes saburrae), banded blenny (Paraclinus fasciatus), twospot cardinalfish (Apogon } \\
\text { maculatus), dusky jawfish (Opistognathus whitehursti), ocean surgeon (Acanthurus bahianus), banded butterfly } \\
\text { (Chaetodon striatus), foureye butterfly (Chaetodon capristratus), reef butterfly (Chaetodon sedentarius), spotfin } \\
\text { butterfly (Chaetodon ocellatus), French angel (Pomacanthus paru), queen angel (Holacanthus ciliaris), sergeant }\end{array}$ \\
\hline
\end{tabular}




\begin{abstract}
Shrimps
Large crabs

Meiofauna

Focal functional group

Focal functional group

Biotic resource
\end{abstract}

Small infauna

Small mobile epifauna

Bivalves

Echinoderms and

gastropods

Zooplankton

Phytoplankton
Biotic resource

Biotic resource

Biotic resource

Biotic resource

Biotic resource

Biotic resource major damsel (Abudefduf saxatilis), blue parrot (Scarus coeruleus), queen parrot (Scarus vetula), rainbow parrot (Scarus guacamaia), redband parrot (Sparisoma aurofrenatum), spotlight parrot (Sparisoma viride), midnight parrotfish (Scarus coelestinus), princess parrotfish (Scarus taeniopterus), yellow chub (Kyphosus incisor), redtail parrotfish (Sparisoma chrysopterum), bucktooth parrotfish (Sparisoma radians)

Pink shrimp (Farfantepenaeus duorarum), white shrimp (Litopenaeus setiferus)

Blue crab (Callinectes sapidus)

Hexanauplia spp.*, Secernentea spp.*, Dorylaimida spp.*, Enoplea spp.*, Maxillopoda spp., Macrodasyida spp.*, Chaetonotida spp.*, Bdelloidea spp.*, Monogonta spp.*

Aplacophora spp.*, Polychaeta spp.

Ostracoda spp.*, Turbellaria spp.*, Cladocera spp.*, Brachiopoda spp.*

Bivalvia spp.

Asteroidea spp., Echinoidea spp., Gastropoda spp., Holothuroidea spp.

Zooplankton

Phytoplankton 
To obtain OSMOSE parameter estimates for the West Florida Shelf ecosystem with our web application, we proceeded as follows. First, in the first page of the web UI, we selected the Gulf of Mexico (Fig. 2). Second, in the second page of the web UI, we employed the different tools available (i.e., the check boxes, the Edit tools and the Plus button; Fig. 3) to define focal functional groups and biotic resources according to Table 5. With respect to biotic resources, there was at the time of writing (September 2018) no information available in SeaLifeBase for some of the classes comprising the meiofauna and small infauna groups and all of the classes comprising the small mobile epifauna group; this entails that we were unable to define a small mobile epifauna group for the West Florida Shelf ecosystem with the web application. Third, we re-ordered focal functional groups and biotic resources according to Table 5. Fourth, we indicated to the web UI that the OSMOSE model for the West Florida Shelf has a monthly time step, i.e., we set the number of time steps per year to 12 in the fifth page of the web UI. Finally, we pressed the "Submit" button in the last page of the web UI to obtain an "osmose_config.zip" file containing all the OSMOSE configuration files populated by the web API. The entire process took around 15 minutes with a laptop with a $2.6 \mathrm{GHz}$ Intel Core i5-6440HQ processor.

To compare the information provided by our web application to the information used in OSMOSE-WFS papers (Grüss et al., 2015, 2016b, 2016c), we examined the following: (1) the length-at-age relationship of focal functional groups; (2) the weight-at-age relationship of focal functional groups; (3) the longevity (i.e., maximum age), body size at sexual maturity, relative fecundity (i.e., annual number of eggs per g of mature female), reproduction seasonality, minimum and maximum predator/prey size ratios, accessibility coefficients, annual natural mortality rate due to marine organisms and events (e.g., harmful algal blooms) that are not explicitly considered in OSMOSE, critical predation efficiency, maximum annual ingestion rate, proportion of females, egg size, and egg weight of focal functional groups; and (4) the theoretical accessibility coefficients, minimum and maximum sizes, and TL of biotic resources.

We first examine the length-at-age relationship of the 12 focal functional groups represented in the OSMOSE-WFS model (Fig. 4). In OSMOSE, schools are assumed to grow in size only when the amount of food they ingested fulfills maintenance requirements, and, if that condition is met, the growth in length of schools is calculated as a function of predation efficiency and the mean length increase from the von Bertalanffy growth model (Appendix A). The length-at-age relationships we examine here were established outside of OSMOSE 
(i.e., ignore predation efficiencies) from the values of the following parameters: (1) instantaneous growth rate at small size $\left(K\right.$, in year $\left.{ }^{-1}\right)$; $(2)$ asymptotic size $\left(L_{\infty}\right.$, in $\left.\mathrm{cm}\right) ;(3)$ theoretical age of zero length ( $t_{0}$, in years); and (4) the age below which a linear function is employed, and above which a von Bertalanffy growth function is employed, to model body growth ( $A_{\text {thres }}$, in years) (Appendix A). The length-at-age relationships established from the parameter estimates provided by the web application and from the parameter estimates used in OSMOSE-WFS papers are similar (Fig. 4). The largest discrepancies between OSMOSEWFS and our web application were observed for reef carnivores and shrimps (Fig. 4).
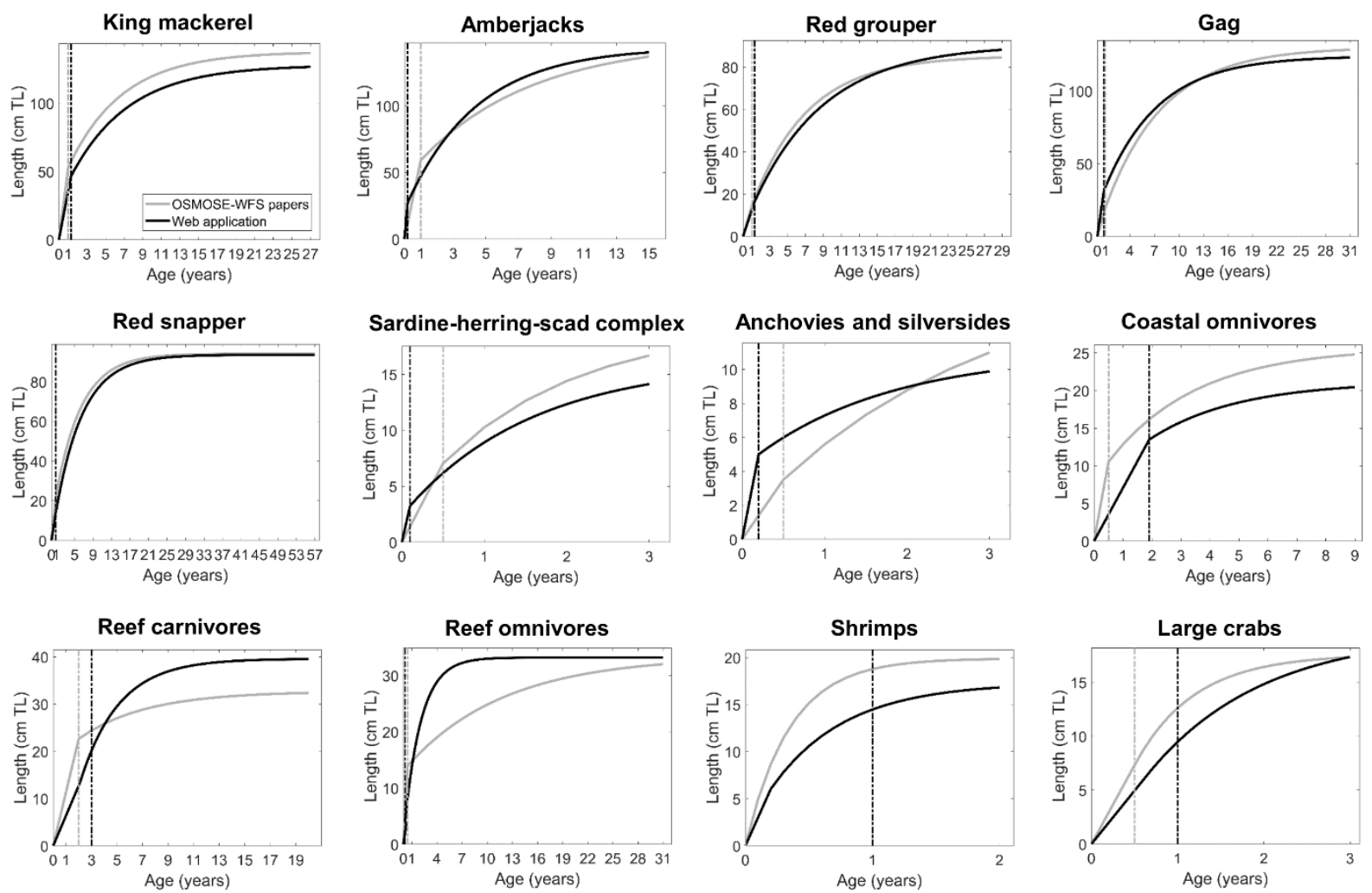

Fig. 4. Comparison of the length-at-age relationships used in previous papers (Grüss et al., 2015, 2016b, 2016c; gray curves) and predicted by our web application (black curves) for the 12 focal functional groups represented in the OSMOSE model of the West Florida Shelf ("OSMOSE-WFS"). The vertical lines indicate the age below which a linear function is employed, and above which a von Bertalanffy growth function is employed, to model body growth.

We next examine the weight-at-age relationship of the 12 focal functional groups represented in OSMOSE-WFS (Fig. 5). In OSMOSE, the body weight of a school is estimated from its body length using a classic allometric function, while the body length of 
the school is itself estimated based on von Bertalanffy parameters and predation efficiency, as explained earlier. The weight-at-age relationships we examine here were also established outside of OSMOSE (i.e., they also ignore predation efficiencies), from the values of the following parameters: (1) the von Bertalanffy parameters $K, L_{\infty}$ and $t_{0}$; (2) the $A_{\text {thres }}$ parameter; and (3) the constant of proportionality $(c)$ and exponent $(b)$ of the allometric length-weight relationship (Appendix A). The weight-at-age relationships established from the parameter estimates provided by the web application and from the parameter estimates used in OSMOSE-WFS papers tend to be similar (Fig. 5). However, the individual body weights of red snapper (Lutjanus campechanus), the sardine-herring-scad complex, the anchovies and silversides' group and shrimps are noticeably larger when employing the parameter estimates used in OSMOSE-WFS papers, while the individual body weights of reef omnivores and large crabs are generally markedly larger when employing the parameter estimates provided by the web application (Fig. 5). Yet, these differences usually do not alter the rankings of the maximum individual body weights of focal functional groups (computed outside of OSMOSE, i.e., ignoring predation efficiencies; Table 6). An exception to this usual pattern is observed for coastal omnivores, whose maximum individual body weight is greater than that of large crabs when employing the parameters used in OSMOSE-WFS papers, while the opposite is observed when the parameters provided by the web application are employed (Table 6). 

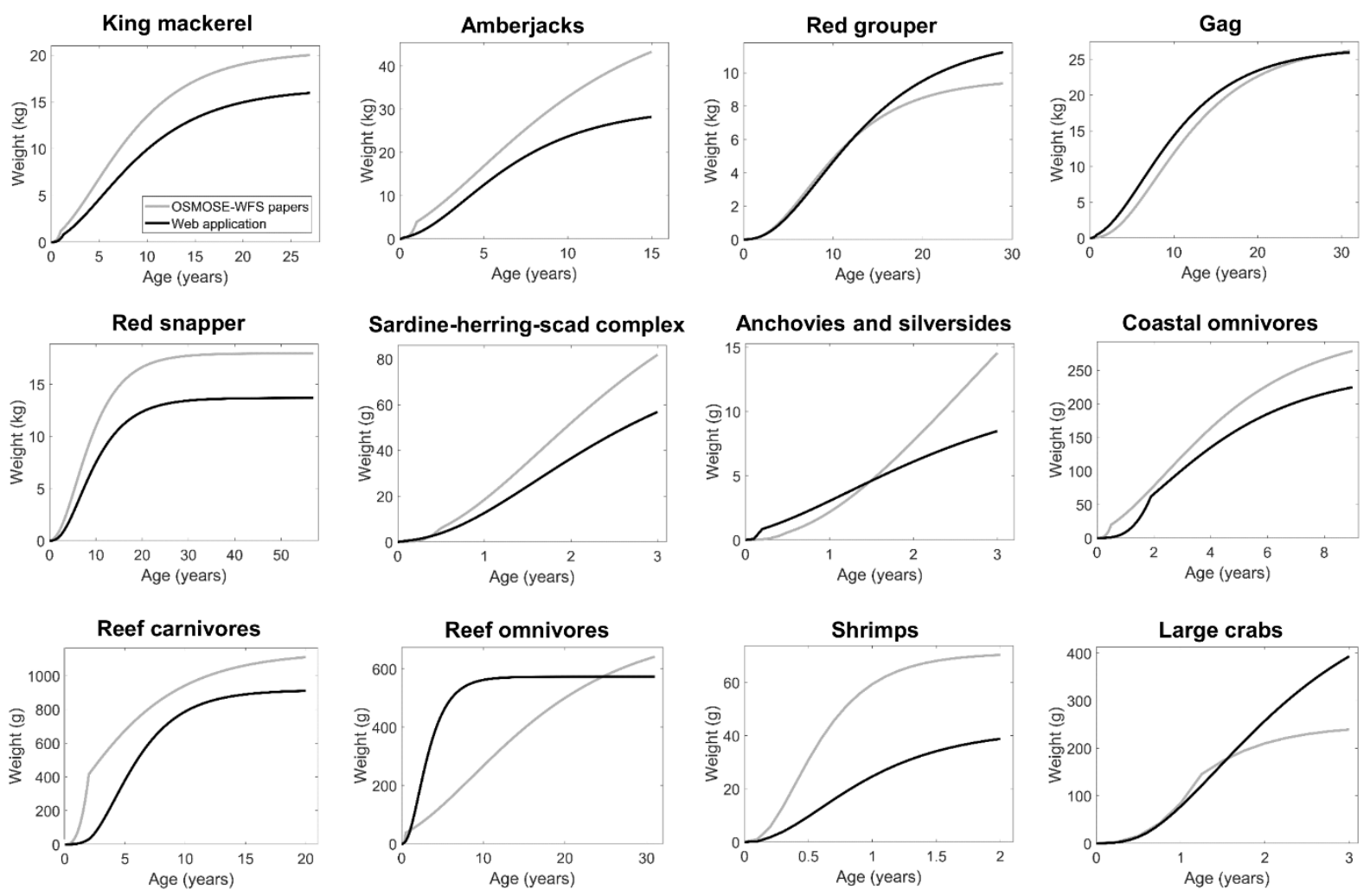

Fig. 5. Comparison of the weight-at-age relationships used in previous papers (Grüss et al., 2015, 2016b, 2016c; gray curves) and predicted by our web application (black curves) for the 12 focal functional groups represented in the OSMOSE model of the West Florida Shelf ("OSMOSE-WFS").

\section{Table 6}

Comparison of the maximum individual body weights of the 12 focal functional groups represented in the OSMOSE-WFS ecosystem model computed outside of OSMOSE (i.e., ignoring predation efficiencies) when using the parameter estimates employed in previous studies (Grüss et al., 2015, 2016b, 2016c) vs. the parameter estimates provided by our web application. Some of the mean individual weights are in $\mathrm{kg}$, while the others are in $\mathrm{g}$.

\begin{tabular}{lll}
\hline Focal functional group & $\begin{array}{l}\text { Maximum individual body } \\
\text { weight when using the parameter } \\
\text { estimates from previous studies }\end{array}$ & $\begin{array}{l}\text { Maximum individual body weight when } \\
\text { using the parameter estimates from the } \\
\text { web application }\end{array}$ \\
\hline Amberjacks & $44.1 \mathrm{~kg}$ & $28.2 \mathrm{~kg}$ \\
$\mathrm{Gag}$ & $26.2 \mathrm{~kg}$ & $26.0 \mathrm{~kg}$ \\
King mackerel & $20.0 \mathrm{~kg}$ & $16.0 \mathrm{~kg}$ \\
Red snapper & $17.9 \mathrm{~kg}$ & $13.7 \mathrm{~kg}$ \\
Red grouper & $9.4 \mathrm{~kg}$ & $11.2 \mathrm{~kg}$ \\
Reef carnivores & $1,109.3 \mathrm{~g}$ & $909.6 \mathrm{~g}$ \\
Reef omnivores & $440.6 \mathrm{~g}$ & $572.7 \mathrm{~g}$ \\
Coastal omnivores & $278.8 \mathrm{~g}$ & $224.7 \mathrm{~g}$ \\
Large crabs & $239.2 \mathrm{~g}$ & $393.2 \mathrm{~g}$ \\
Sardine-herring-scad & $81.8 \mathrm{~g}$ & $56.8 \mathrm{~g}$ \\
complex & & \\
Shrimps & $70.3 \mathrm{~g}$ & $38.8 \mathrm{~g}$
\end{tabular}


We now compare the longevity and body size at sexual maturity $\left(L_{m a t}\right)$ estimates provided by the web application to those used in OSMOSE-WFS papers (Figs. 6A and B). In general, there are no marked differences between the longevity and $L_{m a t}$ estimates delivered by the web application and those used in OSMOSE-WFS papers. Exceptions to this general pattern include: (1) king mackerel (Scomberomorus cavalla), whose longevity is set to 14 years by the web application vs. 27 years in OSMOSE-WFS papers; (2) gag (Mycteroperca microlepis), whose $L_{m a t}$ is set to a larger value by the web application $(63.2 \mathrm{~cm}$ vs. $46.8 \mathrm{~cm}$ in OSMOSE-WFS papers); and (3) reef omnivores, whose longevity is set to 31 years by the web application vs. 17 years in OSMOSE-WFS papers, and whose $L_{\text {mat }}$ is set to a larger value by the web application ( $24.7 \mathrm{~cm}$ vs. $15.5 \mathrm{~cm}$ in OSMOSE-WFS papers).

\section{(A) Longevity}

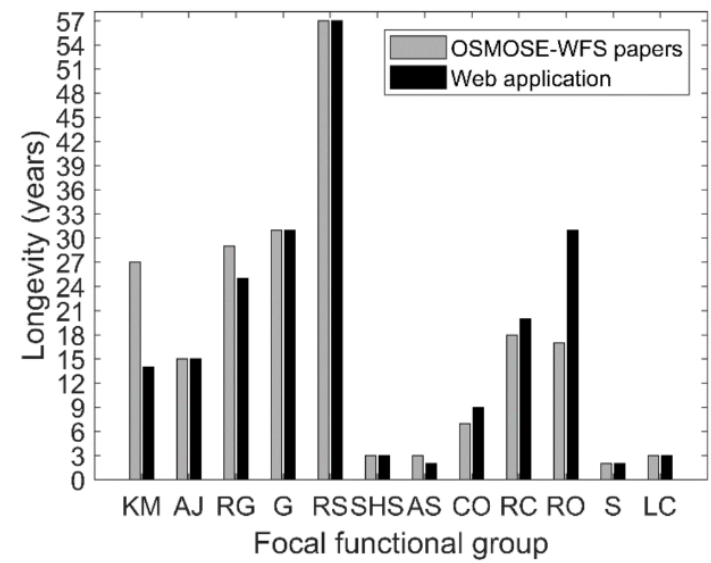

(B) Body length at sexual maturity

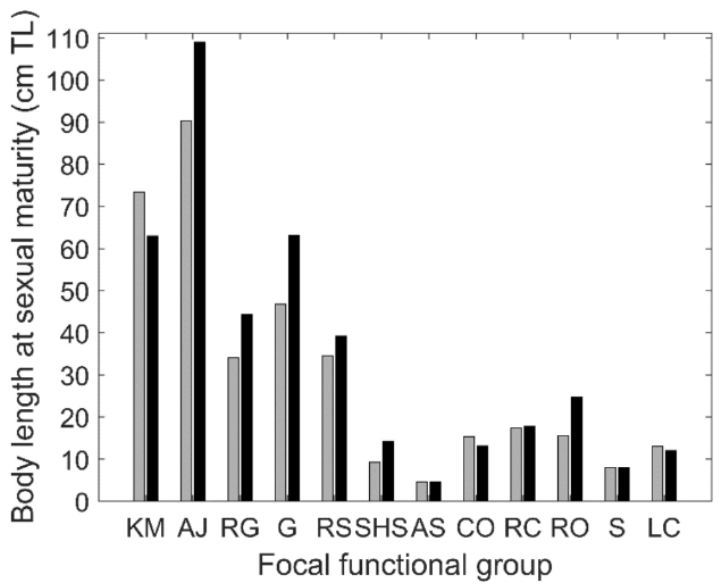

(C) Relative fecundity
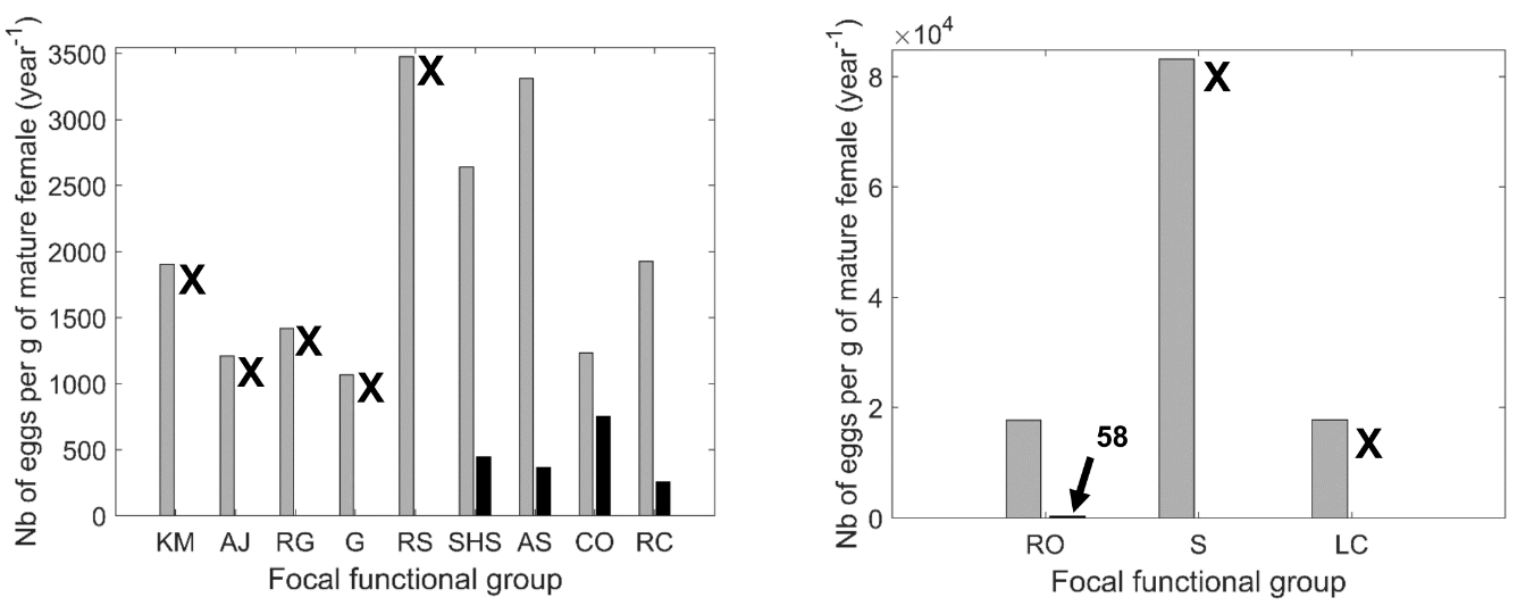
Fig. 6. Comparison of the (A) longevity, (B) body length at sexual maturity and (C) relative fecundity estimates used in previous papers (Grüss et al., 2015, 2016b, 2016c; gray bars) and provided by our web application (black bars) for the 12 focal functional groups represented in the OSMOSE model of the West Florida Shelf (“OSMOSE-WFS”). Relative fecundities are expressed as the annual number of eggs per g of mature female. Black crosses indicate when the web application was unable to provide a relative fecundity estimate. The relative fecundity of reef omnivores estimated by our web application (58 eggs per $\mathrm{g}$ of mature female per year) is pointed out by an arrow. The focal functional groups represented in OSMOSE-WFS include: KM = king mackerel; AJ = amberjacks; RG = red grouper; $\mathrm{G}=$ gag; RS = red snapper; SHS = the sardine-herring-scad complex; $\mathrm{AS}=$ anchovies and silversides $; \mathrm{CO}=$ coastal omnivores; $\mathrm{RC}=$ reef carnivores; $\mathrm{S}=$ shrimps; and $\mathrm{LC}=$ large crabs.

Next, we compare the relative fecundity and reproduction seasonality estimates delivered by the web application to those used in OSMOSE-WFS papers (Figs. 6C and 7). The web application was able to produce a relative fecundity estimate for only five of the 12 focal functional groups represented in the OSMOSE-WFS model: the sardine-herring-scad complex; anchovies and silversides; coastal omnivores; reef carnivores; and reef omnivores (Fig. 6C). For these five focal functional groups, the web application provided a relative fecundity estimate that is considerably smaller than the estimate employed in OSMOSE-WFS papers. Moreover, the web application was able to define reproduction seasonality patterns for only six of the 12 focal functional groups represented in OSMOSE-WFS: amberjacks; red grouper (Epinephelus morio); gag; red snapper; the sardine-herring-scad complex; and large crabs (Fig. 7). For these six focal functional groups, the web application and OSMOSE-WFS papers defined similar reproduction seasonality patterns. When the web application was unable to define reproduction seasonality patterns for a given focal functional group, it assumed that this functional group had a probability of 1/12 to reproduce each month of the year (Fig. 7). 

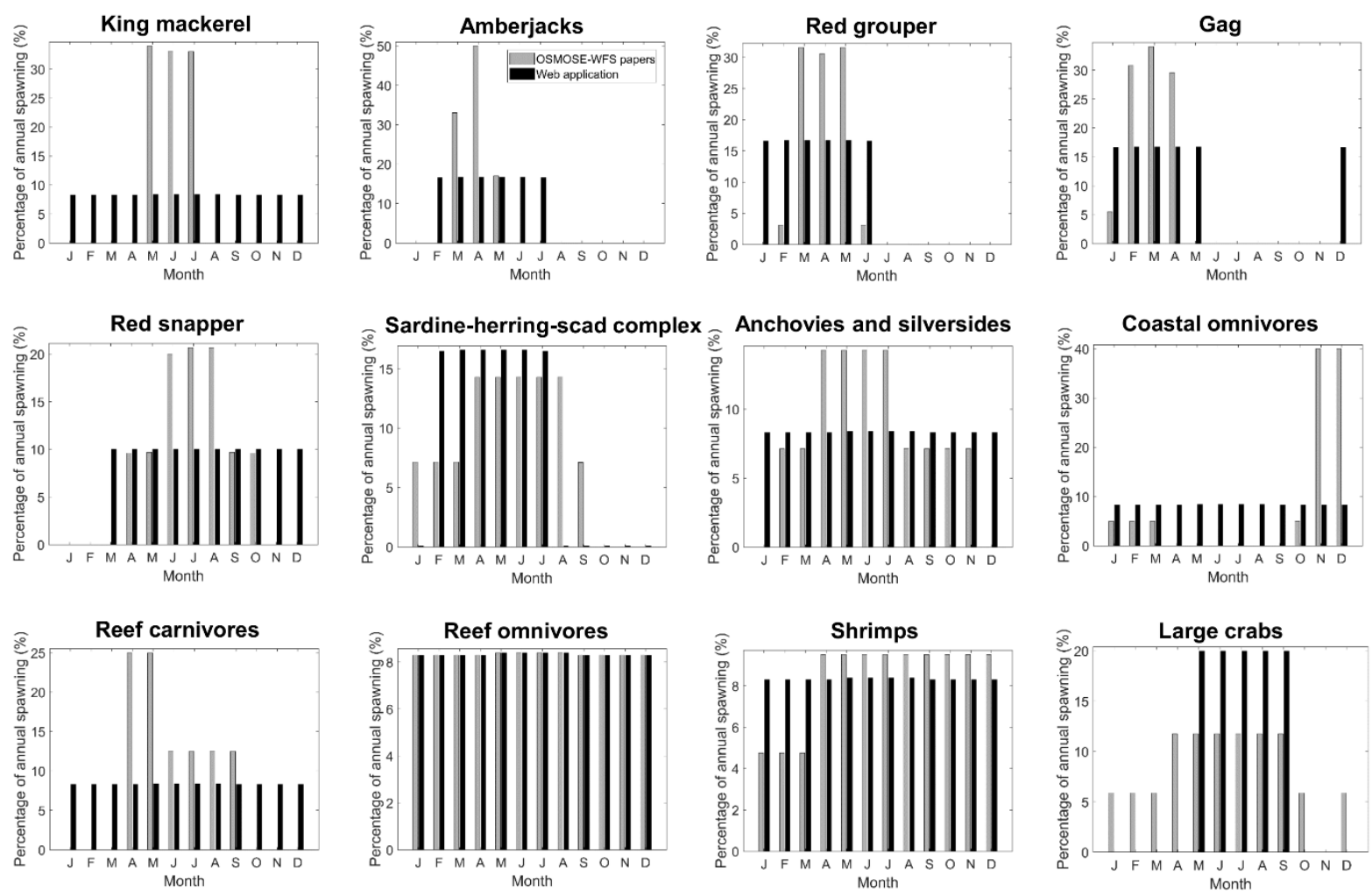

Fig. 7. Comparison of the reproduction seasonalities used in previous papers (Grüss et al., 2015, 2016b, 2016c; gray bars) and estimated by our web application (black bars) for the 12 focal functional groups represented in the OSMOSE model of the West Florida Shelf (“OSMOSE-WFS”).

We now compare the minimum predator/prey size ratio $\left(\left(L_{\text {pred }} / L_{\text {prey }}\right)_{\text {min }}\right)$ and maximum predator/prey size ratio $\left(\left(L_{\text {pred }} / L_{\text {prey }}\right)_{\max }\right)$ estimates provided by the web application to those used in OSMOSE-WFS papers (Figs. 8 and 9). For each focal functional group, the OSMOSE-WFS papers relied on four predator/prey size ratio estimates: one $\left(L_{\text {pred }} / L_{\text {prey }}\right)_{\min }$ estimate for juveniles; one $\left(L_{\text {pred }} / L_{\text {prey }}\right)_{\min }$ estimate for adults; one $\left(L_{\text {pred }} / L_{\text {prey }}\right)_{\max }$ estimate for juveniles; and one $\left(L_{\text {pred }} / L_{\text {prey }}\right)_{\max }$ estimate for adults. In contrast, for each focal functional group, the web application delivers one $\left(L_{\text {pred }} / L_{\text {prey }}\right)_{\min }$ estimate for all life stages combined and one $\left(L_{\text {pred }} / L_{\text {prey }}\right)_{\max }$ estimate for all life stages combined. In general, the web application and OSMOSE-WFS papers defined very similar $\left(L_{\text {pred }} / L_{\text {prey }}\right)_{\min }$ estimates (Figs. 8 and 9$)$. Exceptions to these general patterns occurred for three focal functional groups, for which the web application defined a markedly smaller $\left(L_{\text {pred }} / L_{\text {prey }}\right)_{\min }$ estimate: the sardine-herring-scad complex; anchovies and silversides; and coastal omnivores (Figs. 9A-C). On the other hand, there are marked differences between the $\left(L_{\text {pred }} / L_{\text {prey }}\right)_{\max }$ estimates delivered by the web application and those employed in OSMOSE-WFS papers (Figs. 8 and 9). In general, the web application defined larger $\left(L_{\text {pred }} / L_{\text {prey }}\right)_{\max }$ values than OSMOSE-WFS papers. Exceptions to 
this general pattern included: (1) large crabs and shrimps, for which the web application provided a smaller $\left(L_{\text {pred }} / L_{\text {prey }}\right)_{\max }$ estimate (Figs. $8 \mathrm{~F}$ and $9 \mathrm{~F}$ ); and (2) the sardine-herring-scad complex, for which the web application delivered a $\left(L_{\text {pred }} / L_{\text {prey }}\right)_{\max }$ estimate much larger than the estimate defined for juveniles in OSMOSE-WFS papers, but substantially smaller than the estimate defined for adults in OSMOSE-WFS papers (Fig. 9A). 


\section{(A) King mackerel}

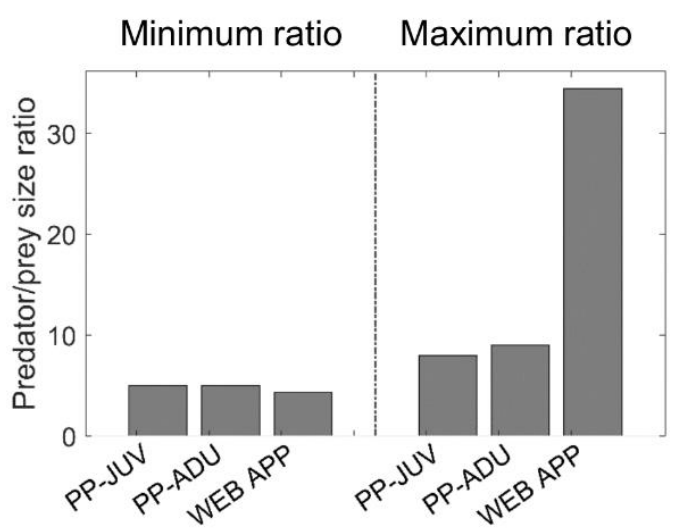

(D) Gag

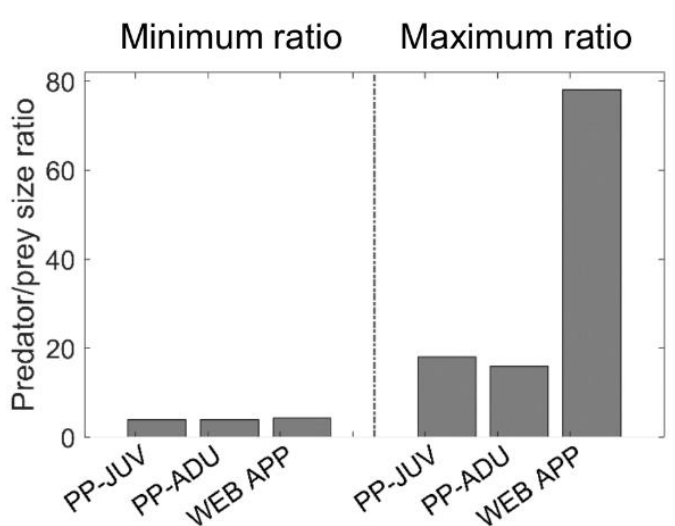

(B) Amberjacks

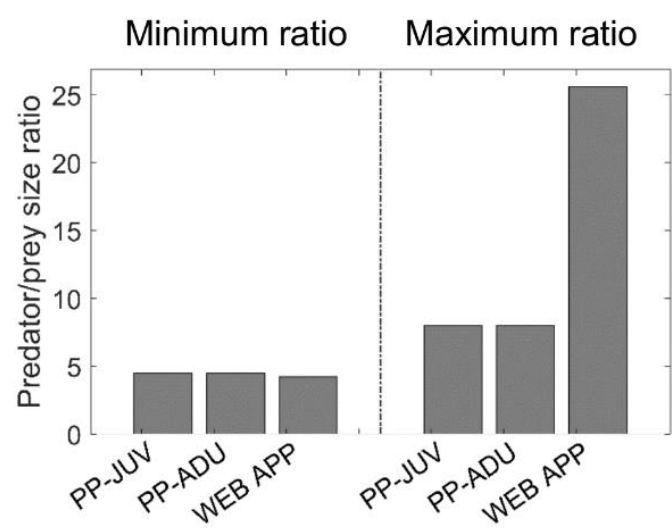

(E) Red snapper

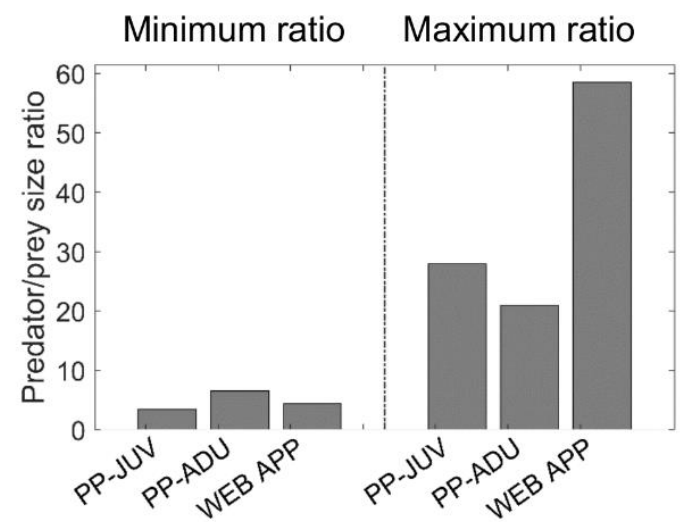

(C) Red grouper

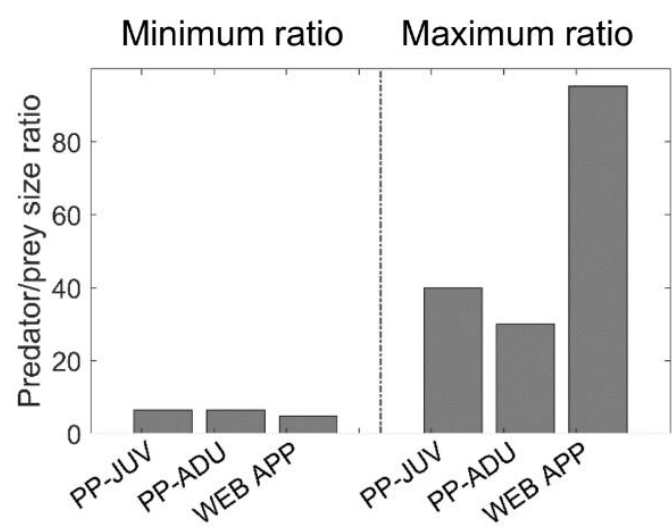

\section{(F) Large crabs}

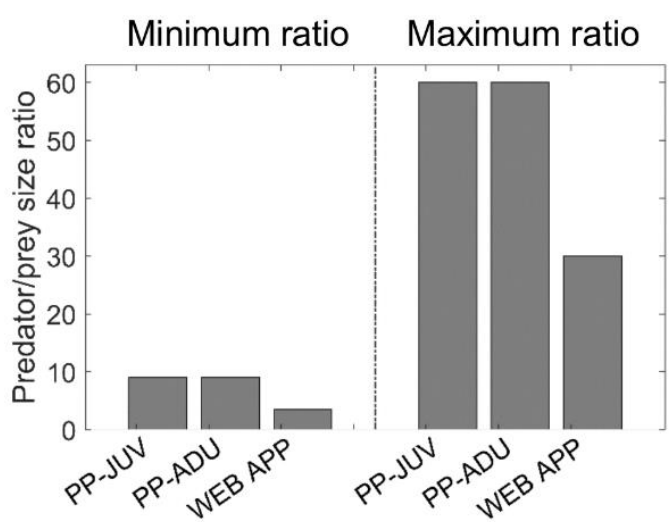

Fig. 8. Comparison of the minimum and maximum predator/prey size ratios used in previous papers (Grüss et al., 2015, 2016b, 2016c) and estimated by our web application for six of the 12 focal functional groups represented in the OSMOSE model of the West Florida Shelf ("OSMOSE-WFS"): (A) king mackerel; (B) amberjacks; (C) red grouper; (D) gag; (E) red snapper; and (F) large crabs. Previous papers defined minimum and maximum predator/prey size ratios for the juvenile and adult stages of focal functional groups (PP-JUV and PP-ADU, respectively), while our web application estimated minimum and maximum predator/prey size ratios for all the life stages of focal functional groups combined (WEB APP). 
(A) Sardine-herring-scad complex

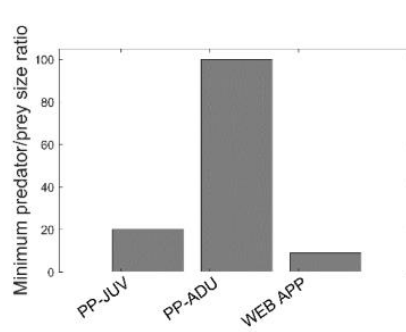

(C) Coastal omnivores

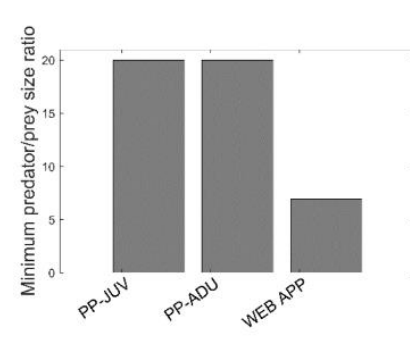

(E) Reef omnivores

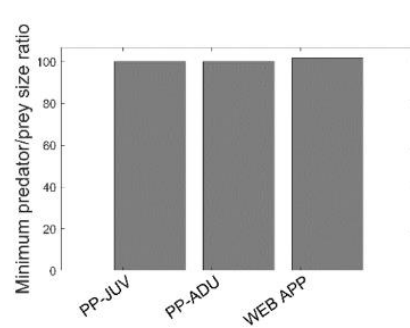

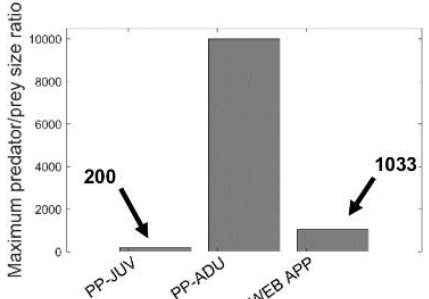
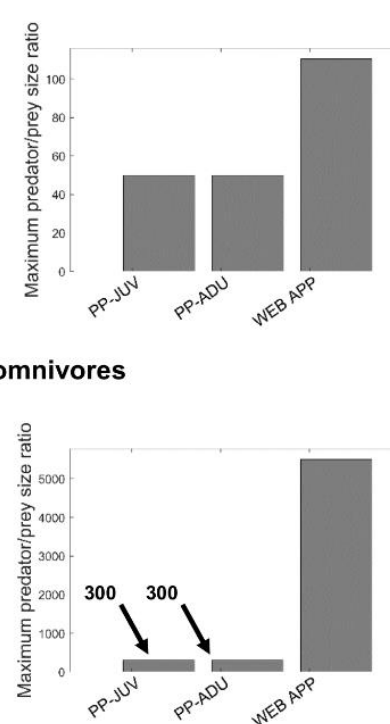

(B) Anchovies and silversides

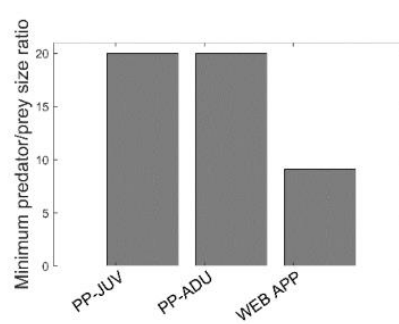

(D) Reef carnivores

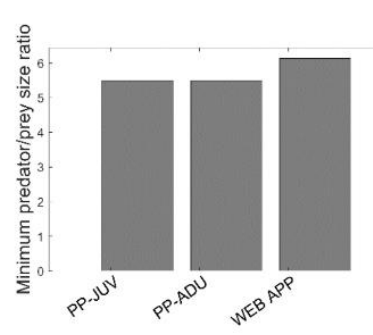

(F) Shrimps

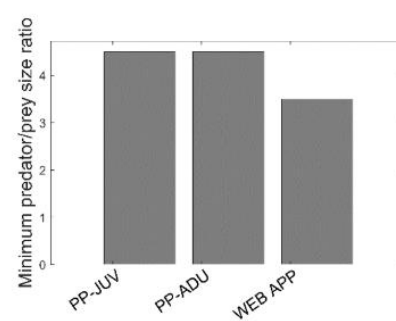

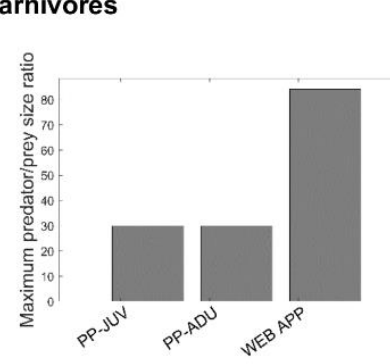
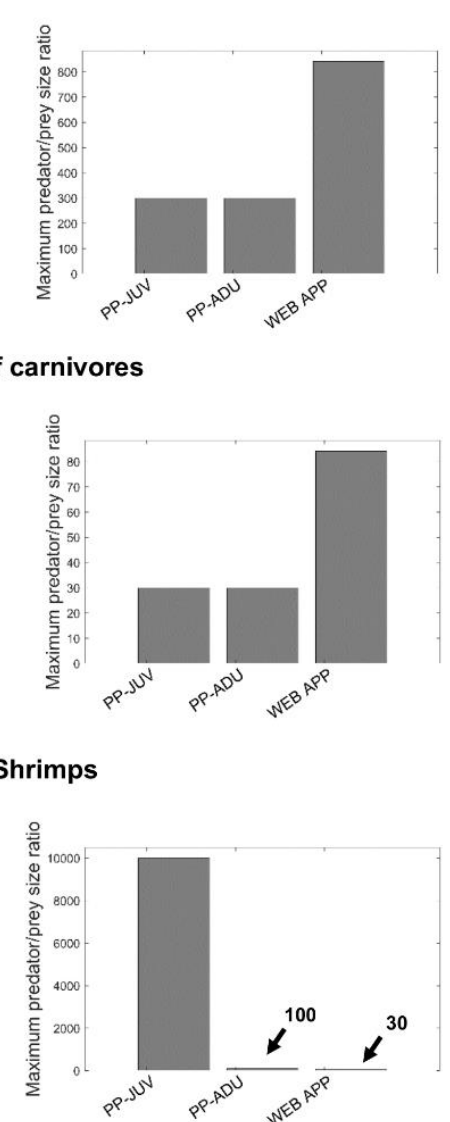

Fig. 9. Comparison of the minimum and maximum predator/prey size ratios used in previous papers (Grüss et al., 2015, 2016b, 2016c) and estimated by our web application for six of the 12 focal functional groups represented in the OSMOSE model of the West Florida Shelf (“OSMOSE-WFS"): (A) the sardine-herring-scad complex; (B) anchovies and silversides; (C) coastal omnivores; (D) reef carnivores; (E) reef omnivores; and (F) shrimps. Previous papers defined minimum and maximum predator/prey size ratios for the juvenile and adult stages of focal functional groups (PP-JUV and PP-ADU, respectively), while our web application estimated minimum and maximum predator/prey size ratios for all the life stages of focal functional groups combined (WEB APP). 
We now compare the accessibility coefficients of focal functional groups and the theoretical accessibility coefficients of biotic resources that are provided by the web application to the coefficients that are used in the OSMOSE-WFS papers (Appendix D). These two types of coefficients describe the accessibility of a potential prey item (the age class of a focal functional group or a biotic resource) to a potential predator (a given age class of a focal functional group). The web application set accessibility coefficients to 0.8 much more often than OSMOSE-WFS papers (Appendix D). The web application set accessibility coefficients to 0.4 only when there was limited overlap in the water column between the potential prey item and the potential predator (e.g., the accessibility of adults of anchovies and silversides, which are pelagic, to adult large crabs, which is benthic, was set to 0.4 ). With respect to the generic phytoplankton and zooplankton groups, the web application automatically sets all of their theoretical accessibility coefficients to 1, while OSMOSE-WFS papers set some of their accessibility coefficients to 0 (e.g., their theoretical accessibility to adult red snapper; Appendix D). With respect to the other biotic resources defined with the web application (i.e., meiofauna, small infauna, bivalves, and echinoderms and gastropods), their theoretical accessibility coefficients were usually set to 0.4 , reflecting their limited overlap in the water column with the great majority of the focal functional groups represented in the OSMOSE-WFS model (Appendix D).

Next, we compare the annual natural mortality rates due to marine organisms and events not explicitly considered in OSMOSE that are provided by the web application to those that are used in the OSMOSE-WFS papers (Table 7). These types of mortality rates are referred to as "diverse natural mortality rates". The web application was able to deliver an estimate different from the 0.2 year $^{-1}$ default value for only four of the 12 focal functional groups represented in OSMOSE-WFS: red snapper; the sardine-herring-scad complex; anchovies and silversides; and reef carnivores (Table 7). The diverse natural mortality rates of red snapper and of the sardine-herring-scad complex delivered by the web application and those employed in OSMOSE-WFS papers are similar. By contrast, the diverse natural mortality rate of anchovies and silversides used in OSMOSE-WFS papers is $c a$. twice larger than that provided by the web application, while the diverse natural mortality rate of reef carnivores delivered by our web application is around twice larger than that employed in OSMOSE-WFS papers (Table 7). 


\section{Table 7}

Comparison of the "diverse natural mortality rate" estimates used in previous papers (Grüss et al., 2015, 2016b, 2016c) and provided by our web application for the 12 focal functional groups represented in the OSMOSE model of the West Florida Shelf (“OSMOSE-WFS"). "Diverse natural mortality" is the mortality due to marine organisms and events (e.g., harmful algal blooms) that are not explicitly considered in OSMOSE.

\begin{tabular}{lll}
\hline Focal functional group & $\begin{array}{l}\text { Diverse natural mortality estimate } \\
\text { in OSMOSE-WFS papers (year-1) }\end{array}$ & $\begin{array}{l}\text { Diverse natural mortality estimate } \\
\text { provided by our web application (year } \\
\text { 1) }\end{array}$ \\
\hline King mackerel & 0.28 & 0.2 \\
Amberjacks & 0.01 & 0.2 \\
Red grouper & 0.02 & 0.2 \\
Gag & 0.01 & 0.2 \\
Red snapper & 0.19 & 0.25 \\
Sardine-herring-scad complex & 1.43 & 1.09 \\
Anchovies and silversides & 2.29 & 1.05 \\
Coastal omnivores & 1.1 & 0.2 \\
Reef carnivores & 0.35 & 0.64 \\
Reef omnivores & 0.55 & 0.2 \\
Shrimps & 1.58 & 0.2 \\
Large crabs & 0.74 & 0.2 \\
\hline
\end{tabular}

We now consider five parameters that are usually set to their default value for all focal functional groups in OSMOSE models: (1) critical predation efficiency (default value: 0.57); (2) maximum annual ingestion rate (default value: 3.5 year $^{-1}$; but see Brochier et al. (2013)); (3) proportion of females (default value: 0.5; but see OSMOSE-WFS papers); (4) egg size (default value: $0.1 \mathrm{~cm}$; but see Halouani et al. (2016)); and (5) egg weight (default value: 0.00053669 g; but see Halouani et al. (2016)). Regarding critical predation efficiency, the web application was able to provide an estimate different from the 0.57 default value for only two of the 12 focal functional groups represented in the OSMOSE-WFS model: red snapper; and reef carnivores (Table 8). The web application was able to deliver a maximum annual ingestion rate estimate different from the 3.5 year $^{-1}$ default value for five of the 12 focal functional groups represented in OSMOSE-WFS: red snapper; the sardine-herring-scad complex; anchovies and silversides; reef carnivores; and reef omnivores (Table 8). The web application set the proportion of females of four of the 12 focal functional groups represented in OSMOSE-WFS to a value different from 0.5: red snapper; anchovies and silversides; reef carnivores; and reef omnivores (Table 8). Finally, the web application set egg size and weight to their default values for all the focal functional groups represented in the OSMOSE-WFS model. 


\section{Table 8}

Estimates of critical predation efficiency, maximum annual ingestion rate and proportion of females provided by our web application for the 12 focal functional groups represented in the OSMOSE model of the West Florida Shelf (“OSMOSE-WFS"). * = The web application set the parameter to its default value, because too little or no information was available in FishBase/SeaLifeBase to produce an estimate.

\begin{tabular}{llll}
\hline Focal functional group & $\begin{array}{l}\text { Critical predation } \\
\text { efficiency }\end{array}$ & $\begin{array}{l}\text { Maximum ingestion } \\
\text { rate }\left(\text { year }^{-1}\right)\end{array}$ & Proportion of females \\
\hline King mackerel & $0.57^{*}$ & $3.5^{*}$ & $0.5^{*}$ \\
Amberjacks & $0.57^{*}$ & $3.5^{*}$ & $0.5^{*}$ \\
Red grouper & $0.57^{*}$ & $3.5^{*}$ & $0.5^{*}$ \\
Gag & $0.57^{*}$ & $3.5^{*}$ & $0.5^{*}$ \\
Red snapper & 0.64 & 5.24 & 0.49 \\
Sardine-herring-scad complex & $0.57^{*}$ & 8.1 & $0.5^{*}$ \\
Anchovies and silversides & $0.57^{*}$ & 10.1 & 0.49 \\
Coastal omnivores & $0.57^{*}$ & $3.5^{*}$ & $0.5^{*}$ \\
Reef carnivores & 0.23 & 7.98 & 0.74 \\
Reef omnivores & $0.57^{*}$ & 3.21 & 0.82 \\
Shrimps & $0.57^{*}$ & $3.5^{*}$ & $0.5^{*}$ \\
Large crabs & $0.57^{*}$ & $3.5^{*}$ & $0.5^{*}$ \\
\hline
\end{tabular}

Finally, we consider the minimum size, maximum size and TL of biotic resources. The web application and OSMOSE-WFS papers usually provided identical minimum size, maximum size and TL estimates for phytoplankton and zooplankton. The exception to this usual pattern was the TL of zooplankton, which was set to a slightly higher value in OSMOSE-WFS papers than in the configuration files delivered by the web application (2.19 vs. 2). The web application was unable to supply any minimum size and maximum size estimates for meiofauna, small infauna, bivalves, and echinoderms and gastropods. It was also unable to supply a TL estimate for meiofauna. The TL values provided by the web application and OSMOSE-WFS papers for small infauna and bivalves were similar (web application: 2 for both biotic resources; OSMOSE-WFS papers: 2.25 for small infauna, and 2 for bivalves), while the TL of echinoderms and gastropods was set to a larger value in the configuration files delivered by the web application than in OSMOSE-WFS papers (3.3 vs. 2.5).

\section{Discussion}

In the present study, we introduced a web application we created, which generates configuration files for applications of an ecosystem modeling platform, OSMOSE, from FishBase and SeaLifeBase data. Our web application is user-friendly and entirely relies on an openly accessible API and free technologies. We provided a demonstration of this tool by 
querying OSMOSE configuration files for the West Florida Shelf ecosystem. This demonstration showed the potential of our web application, but also highlighted research avenues for enhancing it (see Subsection 4.1). Our web application and its associated resources (its associated GitHub repositories, and Appendix A of the present paper) contribute to the "toolkit for OSMOSE users" (Table 9).

\section{Table 9}

Resources of the toolkit for OSMOSE users.

\begin{tabular}{|c|c|}
\hline Resource & Comments \\
\hline User guide & $\begin{array}{l}\text { This resource is currently being developed (https://documentation.osmose- } \\
\text { model.org). Its dedicated GitHub repository is: https://github.com/osmose- } \\
\text { model/user_documentation. }\end{array}$ \\
\hline $\begin{array}{l}\text { Reference paper on } \\
\text { OSMOSE }\end{array}$ & $\begin{array}{l}\text { This resource is currently being developed. Meanwhile, Appendix A of the } \\
\text { present paper is a useful resource. }\end{array}$ \\
\hline OSMOSE Java code & $\begin{array}{l}\text { The Java code of the latest version of OSMOSE (considered in the present } \\
\text { paper), i.e. OSMOSE v3u2, is available for download from } \\
\text { http://www.osmose-model.org/downloads. }\end{array}$ \\
\hline $\begin{array}{l}\text { Template OSMOSE } \\
\text { configuration files }\end{array}$ & $\begin{array}{l}\text { The template configuration files for OSMOSE v3u2 can be downloaded from } \\
\text { http://www.osmose-model.org/downloads. }\end{array}$ \\
\hline Our web application & $\begin{array}{l}\text { The web application introduced in the present paper provides OSMOSE } \\
\text { configuration files for any marine region that is of interest to the user. The } \\
\text { Github repositories dedicated to this tool are: https://github.com/osmose- } \\
\text { model/osmose-model.github.io, https://github.com/osmose-model/osmose- } \\
\text { web-api and https://github.com/osmose-model/osmose-web-api-js. }\end{array}$ \\
\hline Calibration guidelines & $\begin{array}{l}\text { This resource is currently being developed and can be found in its } \\
\text { preliminary form in OSMOSE user guide (https://documentation.osmose- } \\
\text { model.org). Oliveros-Ramos (2014), Oliveros-Ramos and Shin (2016) and } \\
\text { Oliveros-Ramos et al. (2017) are other useful resources. }\end{array}$ \\
\hline $\begin{array}{l}\text { Postprocessing of OSMOSE } \\
\text { outputs }\end{array}$ & $\begin{array}{l}\text { A R package called "osmose", which is now available on CRAN, was } \\
\text { primarily developed for OSMOSE output post-processing. The Github } \\
\text { repository dedicated to this R package is: } \underline{\text { https://github.com/osmose- }} \\
\text { model/osmose. }\end{array}$ \\
\hline OSMOSE user forum & $\begin{array}{l}\text { OSMOSE users can ask questions to other users and OSMOSE developers on } \\
\text { the following webpage: http://www.osmose-model.org/forum. }\end{array}$ \\
\hline
\end{tabular}

A key resource for our web application are its dedicated GitHub repositories (https://github.com/osmose-model/osmose-model.github.io, https://github.com/osmosemodel/osmose-web-api and https://github.com/osmose-model/osmose-web-api-js). Among other purposes, these GitHub repositories intend to keep track of the issues faced by the developers and users of the web application and to find solutions to these issues and, more generally, ways to continuously enhance the web application. We strongly encourage the users of our web application to remain critical towards the OSMOSE parameter values provided by the web application and to accept or reject these values based on their expertise 
of their study marine region. Users are strongly encouraged to create new issues in the GitHub repositories: (1) to indicate critical missing parameter values (e.g., parameter values missing for species that are emblematic to a marine region or of high economic importance to that region); (2) to indicate problematic parameter values; but, also: (3) to provide suggestions as to how the web application could come up with better estimates for the parameters it currently covers and with non-default values for the parameters it currently does not cover.

In our demonstration, we simply examined the parameter estimates for the West Florida Shelf delivered by the web application and did not attempt to re-calibrate the OSMOSE-WFS model. In brief, the calibration of OSMOSE is a process which, usually: (1) ensures that, on average, the biomasses of focal functional groups predicted by OSMOSE are within realistic intervals; and (2) enables the estimation of two types of parameters, the larval mortality rates of focal functional groups and the availability coefficients of biotic resources (Oliveros-Ramos and Shin, 2016). In general, the calibration process of OSMOSE also involves refining the minimum and maximum predator/prey size ratios of focal functional groups to help the biomasses of focal functional groups predicted by the OSMOSE model to be, on average, within realistic intervals (Grüss et al., 2015, 2016c). The calibration of an OSMOSE model is the most difficult process that OSMOSE users have to go through and can easily take several months (Oliveros Ramos, 2014; Grüss et al., 2016c). For this reason, we did not try to re-calibrate the OSMOSE-WFS model for the present study. This endeavor was also beyond the scope of the present study. However, the evaluation of our web application did not require a calibrated OSMOSE model and it was possible to conduct this evaluation directly from the OSMOSE configuration files provided by the web application.

In the following, we first discuss the insights provided by our demonstration for the West Florida Shelf ecosystem and identify attendant avenues for future research. Then, we identify other avenues for future research. The sets of research recommendations we are providing below are certainly not exhaustive and, again, we strongly encourage the users of our web application to suggest other research recommendations as they see fit by opening new issues in our GitHub repositories (https://github.com/osmose-model/osmosemodel.github.io and https://github.com/osmose-model/osmose-web-api).

\subsection{Insights from the demonstration for the West Florida Shelf and attendant avenues for future research}


Overall, the issues we raised earlier during our demonstration for the West Florida Shelf are not worrisome. We discuss below how each of the issues raised can be addressed, and we also identify the OSMOSE parameters that should be the main focus of future research efforts.

A result that was unexpected was the relatively low longevity of king mackerel defined by the web application (14 years vs. 27 years in OSMOSE-WFS papers). This result can be explained by the fact that the web API derives OSMOSE parameters from global median estimates, while the king mackerel longevity estimate used in OSMOSE-WFS models came from a regional study (SEDAR 5, 2004).

The web application was able to provide a relative fecundity estimate for only five of the 12 focal functional groups represented in the OSMOSE-WFS model, and the resulting estimates were all substantially smaller than the relative fecundity estimates used in OSMOSE-WFS papers. Nevertheless, relative fecundity is the most uncertain OSMOSE parameter (Shin et al., 2004; Travers, 2009; Grüss et al., 2015), so that it is not possible to state whether the relative fecundity estimates derived from the results of regional studies or those derived from FishBase/SeaLifeBase data are more reliable. For example, the web application and OSMOSE-WFS papers established that the relative fecundity of the sardineherring-scad complex was 445 and 2,640 eggs per g of mature female per year, respectively; the estimate used in OSMOSE-WFS papers came from a Gulf of Mexico study on scaled sardine (Harengula jaguana) (Houde, 1976). However, the relative fecundity of Sardinops sagax in the OSMOSE model of the Humboldt ecosystem was 8,000 eggs per g of mature female per year (Marzloff et al., 2009) and that of S. sagax in the OSMOSE model of the Southern Benguela was 2,400 eggs per g of mature female per year (Travers-Trolet et al., 2014a), while the relative fecundity of Sardina pilchardus in the OSMOSE model of the Gulf of Gabes was only 360 eggs per g of mature female per year (Halouani et al., 2016). Another example is that of the anchovies and silversides' group, for which the web application and OSMOSE-WFS papers established a relative fecundity of 366 and 3,313 eggs per g of mature female per year, respectively; the estimate used in OSMOSE-WFS papers came from a study on bay anchovy carried out in Cheasapeake Bay, in the mid-Atlantic region (Wang and Houde, 1995). However, the relative fecundity of Engraulis rigens in the OSMOSE model of the Humboldt ecosystem was 13,200 eggs per g of mature female per year (Marzloff et al., 2009) and that of Engraulis encrasicolus in the OSMOSE model of the Southern Benguela was 8,000 eggs per $g$ of mature female per year (Travers-Trolet et al., 2014a), while the 
relative fecundity of E. encrasicolus in the OSMOSE model of the Gulf of Gabes was only 444.6 eggs per g of mature female per year (Halouani et al., 2016). An important avenue for future research is to populate FishBase/SeaLifeBase tables so that the web application is capable of providing a relative fecundity estimate for as many species/functional groups as possible. More specifically, the literature should be screened to fill in gaps in the columns "SpawningCycles" and "RelFecundityMean" of FishBase/SeaLifeBase table "fecundity" (Table 10).

Overall, the web application delivered satisfactory $\left(L_{\text {pred }} / L_{\text {prey }}\right)_{\min }$ and $\left(L_{\text {pred }} / L_{\text {prey }}\right)_{\max }$ estimates, even if the $\left(L_{\text {pred }} / L_{\text {prey }}\right)_{\max }$ estimates delivered tended to be larger than the $\left(L_{\text {pred }} / L_{\text {prey }}\right)_{\max }$ estimates employed in OSMOSE-WFS papers. For the present study, generalized additive models $(\mathrm{GAMs})$ were fitted to the $\left(L_{\text {pred }} / L_{\text {prey }}\right)_{\min }$ 's and $\left(L_{\text {pred }} / L_{\text {prey }}\right)_{\text {max }}$ 's used in existing OSMOSE models to predict the $\left(L_{\text {pred }} / L_{\text {prey }}\right)_{\min }$ and $\left(L_{\text {pred }} / L_{\text {prey }}\right)_{\max }$ of the species included in FishBase and SeaLifeBase (see Appendix C). The $\left(L_{\text {pred }} / L_{\text {prey }}\right)_{\text {min }}$ and $\left(L_{\text {pred }} / L_{\text {prey }}\right)_{\max }$ estimates employed in published OSMOSE papers were established based on experts' opinion or on the limited diet data for which one had both predator length and prey length information (e.g., Travers, 2009; Grüss et al., 2015; Halouani et al., 2016). Furthermore, as mentioned earlier, the $\left(L_{\text {pred }} / L_{\text {prey }}\right)_{\min }$ and $\left(L_{\text {pred }} / L_{\text {prey }}\right)_{\max }$ estimates initially defined for an OSMOSE model are, in general, tweaked during the calibration process of OSMOSE; $\left(L_{\text {pred }} / L_{\text {prey }}\right)_{\min }$ estimates tend to be increased, while $\left(L_{\text {pred }} / L_{\text {prey }}\right)_{\max }$ estimates tend to be decreased, so as to help the biomasses of focal functional groups to be, on average, within realistic intervals (Grüss et al., 2015, 2016c). Therefore, the fact that two of the $\left(L_{\text {pred }} / L_{\text {prey }}\right)_{\text {min }}$ estimates provided by the web application were markedly smaller than those used in OSMOSE-WFS papers, and the fact that the $\left(L_{\text {pred }} / L_{\text {prey }}\right)_{\text {max }}$ estimates provided by the web application tended to be larger than those used in OSMOSE-WFS papers, are not an issue. Nonetheless, an important avenue for future research is to enhance our web application so that it can deliver potentially differing $\left(L_{\text {pred }} / L_{\text {prey }}\right)_{\min }$ and $\left(L_{\text {pred }} / L_{\text {prey }}\right)_{\max }$ estimates for the juvenile and adult stages of focal functional groups; to enable this, individual statistical models (not necessarily GAMs) should be developed for juvenile and adult fish and juvenile and adult invertebrates. Moreover, to allow $\left(L_{\text {pred }} / L_{\text {prey }}\right)_{\min }$ and $\left(L_{\text {pred }} / L_{\text {prey }}\right)_{\max }$ estimates to be more accurate (e.g., to allow $\left(L_{\text {pred }} / L_{\text {prey }}\right)_{\max }$ estimates to be lower for species like king mackerel, red grouper and gag; Fig. 8), the statistical models developed should be more flexible (i.e. their degree of freedom should be as little restrained as possible), and these models should also 
ideally not be sensitive to correlated continuous predictors so as to be able to integrate as many continuous predictors as possible.

The accessibility coefficients of focal functional groups and the theoretical accessibility coefficients of biotic resources, along with distribution maps and $\left(L_{\text {pred }} / L_{\text {prey }}\right)_{\text {min }}$ and $\left(L_{\text {pred }} / L_{\text {prey }}\right)_{\max }$ estimates, influence predation mortalities and diet compositions in OSMOSE (Grüss et al., 2016c; Fu et al., 2017). However, the great majority of the accessibility coefficients of focal functional groups and of the theoretical accessibility coefficients of biotic resources other than phytoplankton and zooplankton are set to 0.8 in OSMOSE, so as to let diet compositions be determined primarily from the degree of spatial overlap between predators and their potential prey (determined by distribution maps) and size adequacy between predators and their potential prey (determined by $\left(L_{\text {pred }} / L_{\text {prey }}\right)_{\min }$ and ( $\left.L_{\text {pred }} / L_{\text {prey }}\right)_{\max }$ estimates) (Travers, 2009; Grüss et al., 2015). Thus, the accessibility coefficients of focal functional groups and the theoretical accessibility coefficients of biotic resources other than phytoplankton and zooplankton defined by the web application, which are most often equal to 0.8 , are satisfactory. Yet, we envision two avenues for future research with respect to accessibility coefficients and theoretical accessibility coefficients. First, for increased ecological realism in the OSMOSE model, the web API should be able to set the theoretical accessibility of phytoplankton and zooplankton to the adult stages of some focal functional groups to 0 (Travers, 2009; Grüss et al., 2015). Second, still to increase ecological realism in OSMOSE, ecological information should be used by the web API to set some of accessibility coefficients to 0 when predator-prey interactions are not possible (e.g., when the potential prey have spikes that dissuade the predator from attacking them; Fu et al., 2013).

The web application provided a diverse natural mortality rate estimate different from the 0.2 year $^{-1}$ default value for only four of the 12 focal functional groups represented in the OSMOSE-WFS model. This result highlights the need to screen the literature to fill in gaps in the column "mortality" of FishBase/SeaLifeBase table "popqb" (Table 3), so as to enable the web application to set the diverse natural mortality rate of the largest possible number of focal functional groups to a value other than the 0.2 year $^{-1}$ default value. In general, the diverse natural mortality rate of a focal functional group represented in an OSMOSE model is assumed equal to the total predation mortality rate of that functional group in an Ecopath model of the same ecosystem that is due to the marine organisms that are represented in the Ecopath model but not in the OSMOSE model (e.g., Marzloff et al., 2009; Travers-Trolet et al., 2014a; Grüss et al., 2015; Halouani et al., 2016). Recently, a large repository called 
"EcoBase" was constructed to gather a very large fraction of the EwE models published around the world (Colléter et al., 2015). Thus, we envision building upon the EcoBase repository to develop a database gathering predation mortality rate estimates for the species included in FishBase and SeaLifeBase for various marine regions. It would then be possible for the web API to query this new database to derive diverse natural mortality rate estimates for an OSMOSE model, given the ultimate focal functional groups defined for that OSMOSE model via the interactions between the web UI and the user.

The web application was able to deliver a non-default estimate for only two of the 12 OSMOSE-WFS focal functional groups with respect to critical predation efficiency, five OSMOSE-WFS focal functional groups with respect to maximum annual ingestion rate, and four OSMOSE-WFS focal functional groups with respect to proportion of females. An avenue for future research is to screen the literature to fill in gaps in relevant FishBase/SeaLifeBase tables, so as to enable the web application to provide non-default estimates of critical predation efficiency, maximum annual ingestion rate and proportion of females for as many species/functional groups as possible (Table 10). However, because critical predation efficiency, maximum annual ingestion rate and proportion of females are usually set to their default value for all focal functional groups in OSMOSE models (but see Brochier et al. (2013) and OSMOSE-WFS papers), the above-mentioned research recommendation is secondary compared to others (Table 10).

In addition to relative fecundity and diverse natural mortality rate, the following OSMOSE parameters should be the primary focus of future research efforts: (1) the reproduction seasonality of focal functional groups, given that the web application was able to define reproduction seasonality patterns for only six of the 12 focal functional groups represented in OSMOSE-WFS; and (2) the minimum and maximum sizes and TL of biotic resources, given that the web application was generally unable to provide values for all these parameters for the biotic resources other than phytoplankton and zooplankton that are represented in OSMOSE-WFS. For all these OSMOSE parameters, efforts should be made to screen the literature to fill in gaps in relevant FishBase/SeaLifeBase tables, so as to maximize the chances of the web application providing non-default estimates for them (Table 10). By contrast, we do not recommend more emphasis on the egg size and egg weight of focal functional groups. The web application set these parameters to their default values for all the focal functional groups represented in OSMOSE-WFS. However, these parameters, which have usually been set to their default values in published OSMOSE-WFS models (but see 
Halouani et al. (2016)), have virtually no impact on OSMOSE predictions and, therefore, do not deserve further consideration compared to parameters such as the relative fecundity and reproduction seasonality of focal functional groups (Table 10).

\section{Table 10}

OSMOSE parameters for which efforts should be made to screen the literature to fill in gaps in relevant FishBase/SeaLifeBase tables, so as to maximize the chances of our web application providing a non-default estimate for these parameters.

\begin{tabular}{|c|c|c|}
\hline OSMOSE parameter & $\begin{array}{l}\text { Priority for future } \\
\text { research efforts? }\end{array}$ & $\begin{array}{l}\text { FishBase/SeaLifeBase fields that need to be } \\
\text { populated }\end{array}$ \\
\hline $\begin{array}{l}\text { Relative fecundity of focal } \\
\text { functional groups }\end{array}$ & Yes & $\begin{array}{l}\text { SpawningCycles, and RelFecundityMean } \\
\text { (FishBase/SeaLifeBase table: fecundity) }\end{array}$ \\
\hline $\begin{array}{l}\text { Reproduction seasonality of focal } \\
\text { functional groups }\end{array}$ & Yes & $\begin{array}{l}\text { Jan, Feb, Mar, Apr, May, Jun, Jul, Aug, Sep, Oct, } \\
\text { Nov, and Dec (FishBase/SeaLifeBase table: } \\
\text { spawning) }\end{array}$ \\
\hline $\begin{array}{l}\text { Diverse natural mortality rate of } \\
\text { focal functional groups }\end{array}$ & Yes & mortality (FishBase/SeaLifeBase table: popqb) \\
\hline Minimum size of biotic resources & Yes & LengthMin (FishBase/SeaLifeBase table: popll) \\
\hline Maximum size of biotic resources & Yes & LengthMax (FishBase/SeaLifeBase table: popll) \\
\hline Trophic level of biotic resources & Yes & Troph (FishBase/SeaLifeBase table: estimate) \\
\hline $\begin{array}{l}\text { Critical predation efficiency of } \\
\text { focal functional groups }\end{array}$ & No & $\begin{array}{l}\text { MaintQB, and PopQB (FishBase/SeaLifeBase } \\
\text { table: popqb) }\end{array}$ \\
\hline $\begin{array}{l}\text { Maximum annual ingestion rate of } \\
\text { focal functional groups }\end{array}$ & No & PopQB (FishBase/SeaLifeBase table: popqb) \\
\hline $\begin{array}{l}\text { Proportion of females of focal } \\
\text { functional groups }\end{array}$ & No & $\begin{array}{l}\text { SexRatiomid (FishBase/SeaLifeBase table: } \\
\text { spawning) }\end{array}$ \\
\hline
\end{tabular}

\subsection{Other avenues for future research}

We also envision the following additional improvements: (1) introducing new invertebrate classes in SeaLifeBase and populating SeaLifeBase tables for these new classes; (2) allowing the web API to derive OSMOSE parameter values from the regional estimates available in FishBase/SeaLifeBase rather than from median estimates; (3) improving the computational efficiency of our web application so that there is no restriction on the total (i.e., original plus additional) number of species per functional group included in the JSON data archives; (4) enhancing our web application so that it covers more OSMOSE parameters; (5) allowing the web application to also define "background functional groups" for OSMOSE models; and (6) building upon the generic software architecture on which our web application relies to develop other web applications delivering a diversity of products needed to advance EBFM. 
The demonstration for the West Florida Shelf ecosystem revealed that a number of small invertebrate classes are not covered by SeaLifeBase (Table 5). Importantly, because there is currently no information on the Ostracoda, Turbellaria, Cladocera and Brachiopoda classes in SeaLifeBase, it was impossible to define a small mobile epifauna group for the West Florida Shelf ecosystem. The literature on small invertebrate species is scarce. Yet, if small invertebrate species are considered in an OSMOSE model, they will be represented as biotic resources, for which OSMOSE only needs a limited number of parameters, of which the great majority could be defined somehow. In particular, we suspect that it will be possible to define the minimum and maximum sizes and TL of most of the species belonging to small invertebrate classes. Therefore, we encourage efforts to populate SeaLifeBase tables for species belonging to small invertebrate classes.

There are cases where, for a given species, several values (usually generated by studies conducted in different regions) are available for a given FishBase/SeaLifeBase parameter. In these cases, the web API produces a median estimate for the FishBase/SeaLifeBase parameter before doing any calculations to derive an OSMOSE parameter estimate. However, two populations of the same species inhabiting different regions can differ in many traits (e.g., Branstetter et al., 1987; Carlson et al., 2006; Cope, 2006; Alheit and Pitcher, 2012), notably their body size, which is usually a function of temperature (Pauly, 2010). Therefore, it would be advantageous to improve the web API so that it can select the most appropriate regional estimate for a given FishBase/SeaLifeBase parameter and species rather than relying on a median estimate for that FishBase/SeaLifeBase parameter and species.

For the sake of computational efficiency, the total number of species (i.e., original plus additional) per functional group in JSON data archives is restricted to 30 currently. In the future, this restriction should be abandoned to enable the web API to set the maximum possible number of OSMOSE parameters to their non-default values. However, for this to happen and, also, because our web application will need to be continuously enhanced, it will be necessary to first find a way to improve the computational efficiency of our web application.

There are a couple of OSMOSE parameters that our web application does not cover currently. For example, the web API does not attempt to estimate the maximum annual starvation mortality rate of focal functional groups, which is set to a default value instead $(0.3$ year $^{-1}$ ), as is the case in all existing OSMOSE applications. As previous studies (e.g., Shin and 
Cury, 2001a; Shin et al., 2004; Travers, 2009), we were unable to establish a method for estimating a maximum annual starvation mortality rate for individual species; however, we feel that developing such a method is not a priority for future research efforts. In contrast, it would be interesting to enhance our web application so that it provides a spatial grid for the OSMOSE model and distribution maps for focal functional groups. For example, a page could be added to the web UI to query additional information to the user, including the desired longitudinal and latitudinal ranges of the OSMOSE spatial grid and the desired resolution of that grid. This information would then be handled by a geographic information system (GIS) tool. The GIS tool would produce distribution maps for focal functional groups in the form of CSV files (Appendix B), based on the depth ranges of the species making up the focal functional groups entered in FishBase/SeaLifeBase tables. Finally, the CSV files generated by the GIS tool would be passed to the web API, which would include them in the “osmose_config.zip" file delivered to the user.

The latest version of OSMOSE (OSMOSE v3u2) and our web application consider two types of functional groups: focal functional groups, and biotic resources. However, it is planned to introduce a third type of functional groups in the template version of OSMOSE: "background functional groups". The concept of background functional groups was introduced in Fu et al. (2017). Background functional groups are functional groups that are of secondary importance for the study envisioned by the user, but that have the potential to be non-negligible predators or prey items of focal functional groups. As the full life cycle of background functional groups is not modeled (contrary to focal functional groups), the number of inputs needed for background functional groups is less important than that needed for focal functional groups, but more important than that needed for biotic resources (Fu et al., 2017). Once the next version of OSMOSE that integrates background functional groups is released, we will modify the web application so that it can also deliver parameter estimates for this new type of functional groups.

The software architecture used to build our bridge between FishBase/SeaLifeBase and the OSMOSE ecosystem modeling platform can serve as a basis for designing other advanced web applications processing FishBase/SeaLifeBase data to produce parameter values for other EBFM tools. A logical future use of this software architecture would be the development of web applications producing parameter estimates for Atlantis and $\mathrm{EwE}$ ecosystem models from FishBase/SeaLifeBase data. Such web applications would consider not only the information on fish compiled in FishBase and the information on invertebrates compiled in SeaLifeBase, 
but also the information on other marine organisms compiled in SeaLifeBase. The generic framework we designed could also be used in many other ways, for example, to develop a simple web application defining functional groups for any marine region, or to derive parameter estimates from FishBase/SeaLifeBase data for dynamic multispecies models (Kinzey and Punt, 2009; Holsman et al., 2016). However, it is important to emphasize that the web application bridging FishBase/SeaLifeBase and OSMOSE does not allow for quality control at the species level. Yet, many modelers employ FishBase and SeaLifeBase as starting points for finding parameter values for individual species, which they then possibly alter or replace using available regional information. Thus, we recommend that some of the future versions of our framework do not aggregate species into functional groups and rather provide parameter values for individual species; users will then have the possibility to gauge parameter values for individual species, eventually alter or replace some of these parameter values using regional information, and group some individual species into groups as they see fit.

\section{Acknowledgments}

This work was supported by the National Oceanic and Atmospheric Administration's RESTORE Act Science Program [award NA15NOS4510233 to the University of Miami; and award NA15NOS4510225 to Texas A\&M University-Corpus Christi]. We are grateful to Quantitative Aquatics employees, Evelyn Liu, Scott Chamberlain and Caihong Fu for having provided help or advice at different levels of this study. We thank two anonymous reviewers and the Subject Editor (Kim de Mutsert), whose comments have improved the quality of our manuscript. Author contributions: A.G., M.L.D.P., J.H.P. and D.P. designed the research; A.G., M.L.D.P., J.H.P., J.R.B., C.D.A. and S.R.O. performed the research; A.G., M.L.D.P., J.H.P., J.R.B. and D.P. analyzed the data; and A.G., M.L.D.P., J.H.P., J.R.B., C.D.A., S.R.O., N.B., Y.-J.S., J.S. and D.P. wrote the paper.

\section{Supplementary data}

Supplementary data associated with this article can be found in the online version of the manuscript. 


\section{References}

Ainsworth, C.H., Kaplan, I.C., Levin, P.S., Mangel, M., 2010. A statistical approach for estimating fish diet compositions from multiple data sources: Gulf of California case study. Ecological Applications 20, 2188-2202.

Ainsworth, C.H., Schirripa, M.J., Morzaria-Luna, H.N., 2015. An Atlantis Ecosystem Model for the Gulf of Mexico Supporting Integrated Ecosystem Assessment. NOAA Technical Memorandum NMFS-SEFSC-676, 149 p.

Alheit, J., Pitcher, T.J., 2012. Hake: biology, fisheries and markets. Springer Science \& Business Media, Amsterdam, The Netherlands.

Boettiger, C., Lang, D.T., Wainwright, P.C., 2012. rfishbase: exploring, manipulating and visualizing FishBase data from R. Journal of Fish Biology 81, 2030-2039.

Brand, L.E., Compton, A., 2007. Long-term increase in Karenia brevis abundance along the Southwest Florida Coast. Harmful Algae 6, 232-252.

Branstetter, S., Musick, J.A., Colvocoresses, J.A., 1987. A comparison of the age and growth of the tiger shark, Galeocerdo cuvieri, from off Virginia and from the northwestern Gulf of Mexico. Fishery Bulletin 85, 269-279.

Brochier, T., Ecoutin, J.M., de Morais, L.T., Kaplan, D.M., Lae, R., 2013. A multi-agent ecosystem model for studying changes in a tropical estuarine fish assemblage within a marine protected area. Aquatic Living Resources 26, 147-158.

Carlson, J.K., Sulikowski, J.R., Baremore, I.E., 2006. Do differences in life history exist for blacktip sharks, Carcharhinus limbatus, from the United States South Atlantic Bight and Eastern Gulf of Mexico? Environmental Biology of Fishes 77, 279-292.

Chagaris Jr, D.D., 2013. Ecosystem-based evaluation of fishery policies and tradeoffs on the West Florida Shelf. PhD dissertation, University of Florida, Gainesville, FL.

Christensen, V., Walters, C.J., 2011. Progress in the use of ecosystem modeling for fisheries management. In: Christensen, V., MacLean, J, (Eds.), Ecosystem approaches to fisheries: a global perspective. Cambridge University Press, Cambridge, pp 189-205.

Christensen, V., Walters, C.J., 2004. Ecopath with Ecosim: methods, capabilities and limitations. Ecological Modelling 172, 109-139.

Coll, M., Steenbeek, J., 2017. Standardized ecological indicators to assess aquatic food webs: The ECOIND software plug-in for Ecopath with Ecosim models. Environmental Modelling \& Software 89, 120-130.

Colléter, M., Valls, A., Guitton, J., Gascuel, D., Pauly, D., Christensen, V., 2015. Global overview of the applications of the Ecopath with Ecosim modeling approach using the EcoBase models repository. Ecological Modelling 302, 42-53.

Collie, J.S., Botsford, L.W., Hastings, A., Kaplan, I.C., Largier, J.L., Livingston, P.A., Plagányi, É., Rose, K.A., Wells, B.K., Werner, F.E., 2016. Ecosystem models for fisheries management: finding the sweet spot. Fish and Fisheries 17, 101-125.

Cope, J.M., 2006. Exploring intraspecific life history patterns in sharks. Fishery Bulletin 104, 311-320.

Espinoza-Tenorio, A., Wolff, M., Taylor, M.H., Espejel, I., 2012. What model suits ecosystem-based fisheries management? A plea for a structured modeling process. Reviews in Fish Biology and Fisheries 22, 81-94.

Froese, R., Pauly, D., 2018. FishBase. World Wide Web electronic publication. URL: www.fishbase.org. 
Fu, C., Olsen, N., Taylor, N., Grüss, A., Batten, S., Liu, H., Verley, P., Shin, Y.-J., Link, H. editor: J., 2017. Spatial and temporal dynamics of predator-prey species interactions off western Canada. ICES Journal of Marine Science 74, 2107-2119.

Fu, C., Perry, R.I., Shin, Y.-J., Schweigert, J., Liu, H., 2013. An ecosystem modelling framework for incorporating climate regime shifts into fisheries management. Progress in Oceanography 115, 53-64.

Fu, C., Shin, Y.-J., Perry, R.I., King, J., Liu, H., 2012. Exploring climate and fishing impacts in an ecosystem framework. In: Kruse, G.H., Browman, H.I., Cochrane, K.L., Evans, D., Jamieson, G.S., Livingston, P.A., Woodby, D., Zhang, C.I. (Eds.), Global Progress in Ecosystem-based Fisheries Management. Alaska Sea Grant, University of Alaska Fairbanks, Fairbanks, pp. 65-85.

Fu, C., Travers-Trolet, M., Velez, L., Grüss, A., Bundy, A., Shannon, L.J., Fulton, E.A., Akoglu, E., Houle, J.E., Coll, M., 2018. Risky business: The combined effects of fishing and changes in primary productivity on fish communities. Ecological Modelling 368, 265-276.

Fulton, E.A., 2010. Approaches to end-to-end ecosystem models. Journal of Marine Systems 81, 171-183.

Fulton, E.A., Link, J.S., Kaplan, I.C., Savina-Rolland, M., Johnson, P., Ainsworth, C., Horne, P., Gorton, R., Gamble, R.J., Smith, A.D., 2011. Lessons in modelling and management of marine ecosystems: the Atlantis experience. Fish and Fisheries 12, 171-188.

Fulton, E.A., Parslow, J.S., Smith, A.D., Johnson, C.R., 2004. Biogeochemical marine ecosystem models II: the effect of physiological detail on model performance. Ecological Modelling 173, 371-406.

Fulton, E.A., Smith, A.D.M., Smith, D.C., 2007. Alternative management strategies for southeast Australian commonwealth fisheries: stage 2: quantitative management strategy evaluation. Commonwealth Scientific and Industrial Research Organisation (CSIRO), Hobart, Australia.

Gosling, J., 2000. The Java language specification. Addison-Wesley Professional, Boston, MA.

Grüss, A., Babcock, E.A., Sagarese, S.R., Drexler, M., Chagaris, D.D., Ainsworth, C.H., Penta, B., DeRada, S., Sutton, T.T., 2016a. Improving the spatial allocation of functional group biomasses in spatially-explicit ecosystem models: insights from three Gulf of Mexico models. Bulletin of Marine Science 92, 473-496.

Grüss, A., Drexler, M.D., Chancellor, E., Ainsworth, C.H., Gleason, J.S., Tirpak, J.M., Love, M.S., Babcock, E.A., 2019. Representing species distributions in spatially-explicit ecosystem models from presence-only data. Fisheries Research 210, 89-105.

Grüss, A., Drexler, M.D., Ainsworth, C.H., Babcock, E.A., Tarnecki, J.H., Love, M.S., 2018a. Producing Distribution Maps for a Spatially-Explicit Ecosystem Model Using Large Monitoring and Environmental Databases and a Combination of Interpolation and Extrapolation. Frontiers in Marine Science 5, 16.

Grüss, A., Drexler, M.D., Ainsworth, C.H., Roberts, J.J., Carmichael, R.H., Putman, N.F., Richards, P.M., Chancellor, E., Babcock, E.A., Love, M.S., 2018b. Improving the spatial allocation of marine mammal and sea turtle biomasses in spatially explicit ecosystem models. Marine Ecology Progress Series 602, 255-274.

Grüss, A., Harford, W.J., Schirripa, M.J., Velez, L., Sagarese, S.R., Shin, Y.-J., Verley, P., 2016b. Management strategy evaluation using the individual-based, multispecies modeling approach OSMOSE. Ecological Modelling 340, 86-105.

Grüss, A., Rose, K.A., Simons, J., Ainsworth, C.H., Babcock, E.A., Chagaris, D.D., De Mutsert, K., Froeschke, J., Himchak, P., Kaplan, I.C., others, 2017a. 
Recommendations on the use of ecosystem modeling for informing ecosystem-based fisheries management and restoration outcomes in the Gulf of Mexico. Marine and Coastal Fisheries 9, 281-295.

Grüss, A., Schirripa, M.J., Chagaris, D., Drexler, M., Simons, J., Verley, P., Shin, Y.-J., Karnauskas, M., Oliveros-Ramos, R., Ainsworth, C.H., 2015. Evaluation of the trophic structure of the West Florida Shelf in the 2000s using the ecosystem model OSMOSE. Journal of Marine Systems 144, 30-47.

Grüss, A., Schirripa, M.J., Chagaris, D., Velez, L., Shin, Y.-J., Verley, P., Oliveros-Ramos, R., Ainsworth, C.H., 2016c. Estimating natural mortality rates and simulating fishing scenarios for Gulf of Mexico red grouper (Epinephelus morio) using the ecosystem model OSMOSE-WFS. Journal of Marine Systems 154, 264-279.

Grüss, A., Thorson, J.T., Babcock, E.A., Tarnecki, J.H., 2018c. Producing distribution maps for informing ecosystem-based fisheries management using a comprehensive survey database and spatio-temporal models. ICES Journal of Marine Science 75, 158-177.

Grüss, A., Thorson, J.T., Sagarese, S.R., Babcock, E.A., Karnauskas, M., Walter, J.F., Drexler, M., 2017b. Ontogenetic spatial distributions of red grouper (Epinephelus morio) and gag grouper (Mycteroperca microlepis) in the US Gulf of Mexico. Fisheries Research 193, 129-142.

Halouani, G., Lasram, F.B.R., Shin, Y.-J., Velez, L., Verley, P., Hattab, T., Oliveros-Ramos, R., Diaz, F., Ménard, F., Baklouti, M., 2016. Modelling food web structure using an end-to-end approach in the coastal ecosystem of the Gulf of Gabes (Tunisia). Ecological Modelling 339, 45-57.

Halouani, G., Le Loc'h, F., Shin, Y.J., Velez, L., Hattab, T., Salah Romdhane, M., Ben Rais Lasram, F., 2019. An end-to-end model to evaluate the sensitivity of ecosystem indicators to track fishing impacts. Ecological Indicators 98, 121-130.

Harvey, C.J., Kelble, C.R., Schwing, F.B., 2016. Implementing "the IEA": using integrated ecosystem assessment frameworks, programs, and applications in support of operationalizing ecosystem-based management. ICES Journal of Marine Science 74, 398-405.

Holsman, K.K., Ianelli, J., Aydin, K., Punt, A.E., Moffitt, E.A., 2016. A comparison of fisheries biological reference points estimated from temperature-specific multi-species and single-species climate-enhanced stock assessment models. Deep Sea Research Part II: Topical Studies in Oceanography 134, 360-378.

Houde, E.D., 1976. Abundance and potential for fisheries-development of some sardine-like fishes in the eastern Gulf of Mexico. Proc Gulf Caribb Fish Inst 28, 73-82.

Karnauskas, M., Kelble, C.R., Regan, S., Quenée, C., Allee, R., Jepson, M., Freitag, A., Craig, J.K., Carollo, C., Barbero, L., Trifonova, L., Hanisko, D., Zapfe, G., 2017. Ecosystem status report update for the Gulf of Mexico. NOAA Technical Memorandum NMFS-SEFSC 706, $51 \mathrm{p}$.

Karnauskas, M., Schirripa, M.J., Kelble, C.R., Cook, G.S., Craig, J.K., 2013. Ecosystem status report for the Gulf of Mexico. NOAA Technical Memorandum NMFS-SEFSC 653, $52 \mathrm{p}$.

Kinzey, D., Punt, A.E., 2009. Multispecies and single-species models of fish population dynamics: comparing parameter estimates. Natural Resource Modeling 22, 67-104.

Link, J., 2010. Ecosystem-based fisheries management: confronting tradeoffs. Cambridge University Press, Cambridge, UK.

Marzloff, M., Shin, Y.-J., Tam, J., Travers, M., Bertrand, A., 2009. Trophic structure of the Peruvian marine ecosystem in 2000-2006: insights on the effects of management scenarios for the hake fishery using the IBM trophic model Osmose. Journal of Marine Systems 75, 290-304. 
Masi, M.D., Ainsworth, C.H., Chagaris, D., 2014. A probabilistic representation of fish diet compositions from multiple data sources: a Gulf of Mexico case study. Ecological Modelling 284, 60-74.

Morzaria Luna, H.M., Ainsworth, C.H., Tarnecki, J.H., Grüss, A., 2018. Diet composition uncertainty determines impacts on fisheries following an oil spill. Ecosystem Services 33, 187-198.

O’Farrell, H., Grüss, A., Sagarese, S.R., Babcock, E.A., Rose, K.A., 2017. Ecosystem modeling in the Gulf of Mexico: current status and future needs to address ecosystembased fisheries management and restoration activities. Reviews in Fish Biology and Fisheries 27, 587-614.

Oliveros Ramos, R., 2014. End-to-end modelling for an ecosystem approach to fisheries in the Northern Humboldt Current Ecosystem. PhD thesis, University of Montpellier 2, France.

Oliveros-Ramos, R., Shin, Y.-J., 2016. Calibrar: an R package for fitting complex ecological models. arXiv preprint arXiv:1603.03141.

Oliveros-Ramos, R., Verley, P., Echevin, V., Shin, Y.-J., 2017. A sequential approach to calibrate ecosystem models with multiple time series data. Progress in Oceanography $151,227-244$.

Osmani, A., 2012. Learning JavaScript Design Patterns: A JavaScript and jQuery Developer's Guide. O'Reilly Media, Inc., Sebastopol, CA.

Palomares, M.L.D., Pauly, D., 2018. SeaLifeBase. World Wide Web electronic publication. URL: www.sealifebase.org,

Pauly, D., 2010. Gasping Fish and Panting Squids: Oxygen, Temperature and the Growth of Water-Breathing Animals. Excellence in Ecology (22), International Ecology Institute, Oldendorf/Luhe, Germany, xxviii +216 p.

Pauly, D., Christensen, V., Walters, C., 2000. Ecopath, Ecosim, and Ecospace as tools for evaluating ecosystem impact of fisheries. ICES journal of Marine Science 57, 697706.

Pikitch, E., Santora, C., Babcock, E.A., Bakun, A., Bonfil, R., Conover, D.O., Dayton, others, Doukakis, P., Fluharty, D., Heneman, B., 2004. Ecosystem-based fishery management. Science 305, 346-347.

Plagányi, É.E., 2007. Models for an ecosystem approach to fisheries. FAO Fisheries Technical Paper 477. FAO, Rome, Italy.

Reed, J., Shannon, L., Velez, L., Akoglu, E., Bundy, A., Coll, M., Fu, C., Fulton, E.A., Grüss, A., Halouani, G., 2017. Ecosystem indicators-accounting for variability in species' trophic levels. ICES Journal of Marine Science 74, 158-169.

Sagarese, S.R., Nuttall, M.A., Geers, T.M., Lauretta, M.V., Walter III, J.F., Serafy, J.E., 2016. Quantifying the trophic importance of Gulf menhaden within the northern Gulf of Mexico ecosystem. Marine and Coastal Fisheries 8, 23-45.

SEDAR 5, 2004. Atlantic and Gulf of Mexico king mackerel, complete stock assessment report. Available from: http://www.sefsc.noaa.gov/ sedar/.

Shin, Y.-J., 2000. Interactions trophiques et dynamiques des populations dans les écosystèmes marins exploités. Approche par modélisation individus-centrée. Thèse de doctorat, Université Paris 7 - Denis Diderot, Paris, France.

Shin, Y.-J., Cury, P., 2004. Using an individual-based model of fish assemblages to study the response of size spectra to changes in fishing. Canadian Journal of Fisheries and Aquatic Sciences 61, 414-431.

Shin, Y.-J., Cury, P., 2001a. Exploring fish community dynamics through size-dependent trophic interactions using a spatialized individual-based model. Aquatic Living Resources 14, 65-80. 
Shin, Y.-J., Cury, P., 2001b. Simulation of the effects of marine protected areas on yield and diversity using a multispecies, spatially explicit, individual-based model. In: Kruse, G.H., Browman, H.I., Cochrane, K.L., Evans, D., Jamieson, J.H., Livingston, P.A., Woodby, D., Zhang, C.I. (Eds.), Spatial Processes and management of marine populations. Alaska Sea Grant. University of Alaska Fairbanks, Fairbanks, Alaska, pp. 105-122.

Shin, Y.-J., Houle, J.E., Akoglu, E., Blanchard, J.L., Bundy, A., Coll, M., Demarcq, H., Fu, C., Fulton, E.A., Heymans, J.J., 2018. The specificity of marine ecological indicators to fishing in the face of environmental change: A multi-model evaluation. Ecological Indicators 89, 317-326.

Shin, Y.-J., Shannon, L.J., Cury, P.M., 2004. Simulations of fishing effects on the southern Benguela fish community using an individual-based model: learning from a comparison with ECOSIM. African Journal of Marine Science 26, 95-114.

Smith, A.D., Brown, C.J., Bulman, C.M., Fulton, E.A., Johnson, P., Kaplan, I.C., LozanoMontes, H., Mackinson, S., Marzloff, M., Shannon, L.J., 2011. Impacts of fishing low-trophic level species on marine ecosystems. Science 333, 1147-1150.

Smith, M.D., Fulton, E.A., Day, R.W., Shannon, L.J., Shin, Y.-J., 2015. Ecosystem modelling in the southern Benguela: comparisons of Atlantis, Ecopath with Ecosim, and OSMOSE under fishing scenarios. African Journal of Marine Science 37, 65-78.

Steele, J.H., Aydin, K., Gifford, D.J., Hofmann, E.E., 2013. Construction kits or virtual worlds; Management applications of E2E models. Journal of Marine Systems 109, 103-108.

Tarnecki, J.H., Wallace, A.A., Simons, J.D., Ainsworth, C.H., 2016. Progression of a Gulf of Mexico food web supporting Atlantis ecosystem model development. Fisheries Research 179, 237-250.

Travers, M., 2009. Couplage de modèles trophiques et effets combinés de la pêche et du climat. PhD Thesis, Paris 6, Paris, France.

Travers, M., Shin, Y.-J., 2010. Spatio-temporal variability in fish-induced predation mortality on plankton: A simulation approach using a coupled trophic model of the Benguela ecosystem. Progress in Oceanography 84, 118-120.

Travers, M., Shin, Y.-J., Jennings, S., Machu, E., Huggett, J.A., Field, J.G., Cury, P.M., 2009. Two-way coupling versus one-way forcing of plankton and fish models to predict ecosystem changes in the Benguela. Ecological Modelling 220, 3089-3099.

Travers, M., Shin, Y.-J., Shannon, L., Cury, P., 2006. Simulating and testing the sensitivity of ecosystem-based indicators to fishing in the southern Benguela ecosystem. Canadian Journal of Fisheries and Aquatic Sciences 63, 943-956.

Travers, M., Watermeyer, K., Shannon, L.J., Shin, Y.-J., 2010. Changes in food web structure under scenarios of overfishing in the southern Benguela: comparison of the Ecosim and OSMOSE modelling approaches. Journal of Marine Systems 79, 101-111.

Travers-Trolet, M., Shin, Y.J., Field, J.G., 2014a. An end-to-end coupled model ROMSN2P2Z2D2-OSMOSE of the southern Benguela foodweb: parameterisation, calibration and pattern-oriented validation. African Journal of Marine Science 36, 1129.

Travers-Trolet, M., Shin, Y.-J., Shannon, L.J., Moloney, C.L., Field, J.G., 2014b. Combined fishing and climate forcing in the southern Benguela upwelling ecosystem: an end-toend modelling approach reveals dampened effects. PloS one 9, e94286.

Vergnon, R., Shin, Y.-J., Cury, P., 2008. Cultivation, Allee effect and resilience of large demersal fish populations. Aquatic Living Resources 21, 287-295. 
Walters, C., Christensen, V., Pauly, D., 1997. Structuring dynamic models of exploited ecosystems from trophic mass-balance assessments. Reviews in Fish Biology and Fisheries 7, 139-172.

Wang, S.-B., Houde, E.D., 1995. Distribution, relative abundance, biomass and production of bay anchovy Anchoa mitchilli in the Chesapeake Bay. Marine Ecology Progress Series $121,27-38$.

Xing, L., Zhang, C., Chen, Y., Shin, Y.-J., Verley, P., Yu, H., Ren, Y., 2017. An individualbased model for simulating the ecosystem dynamics of Jiaozhou Bay, China. Ecological Modelling 360, 120-131.

Yemane, D., Shin, Y.-J., Field, J.G., 2009. Exploring the effect of Marine Protected Areas on the dynamics of fish communities in the southern Benguela: an individual-based modelling approach. ICES Journal of Marine Science 66, 378-387. 